\title{
Mildly Oxidized LDL Induces an Increased Apolipoprotein J/Paraoxonase Ratio
}

\author{
Mohamad Navab, ${ }^{*}$ Susan Hama-Levy, ${ }^{*}$ Brian J. Van Lenten, ${ }^{*}$ Gregg C. Fonarow, ${ }^{*}$ Cheryll J. Cardinez, ${ }^{*}$ \\ Lawrence W. Castellani, ${ }^{\star}$ Marie-Luise Brennan, ${ }^{\star \star}$ Aldons J. Lusis, ${ }^{\star \ddagger}$ and Alan M. Fogelman ${ }^{\star}$ \\ *Division of Cardiology, Department of Medicine, School of Medicine, and ${ }^{\ddagger}$ Department of Microbiology and Molecular Genetics, the \\ College of Letters and Sciences, University of California, Los Angeles, California 90095
}

\begin{abstract}
We have examined the effects of mildly oxidized LDL and atherosclerosis on the levels of two proteins associated with HDL; apolipoprotein J (apoJ), and paraoxonase (PON). On an atherogenic diet, PON activity decreased by $52 \%$, and apoJ levels increased 2.8 -fold in fatty streak susceptible mice, C57BL/6J (BL/6), but not in fatty streak resistant mice, $\mathrm{C} 3 \mathrm{H} / \mathrm{HeJ}(\mathrm{C} 3 \mathrm{H})$. Plasma $\mathrm{PON}$ activity was also significantly decreased, and apoJ levels were markedly increased in apolipoprotein $\mathrm{E}$ knockout mice on the chow diet, resulting in a 9.2-fold increase in the apoJ/PON ratio as compared to controls. Furthermore, a dramatic increase in the apoJ/PON ratio (over 100 -fold) was observed in LDL receptor knockout mice when they were fed a $0.15 \%$-cholesterol-enriched diet. Injection of mildly oxidized LDL (but not native $\mathrm{LDL}$ ) into $\mathrm{BL} / 6$ mice (but not in $\mathrm{C} 3 \mathrm{H}$ mice) on a chow diet resulted in a 59\% decrease in PON activity $(P<$ $0.01)$ and a 3.6-fold increase in apoJ levels $(P<0.01)$. When an acute phase reaction was induced in rabbits, or the rabbits were placed on an atherogenic diet, hepatic mRNA for apoJ was increased by 2.7 -fold and 2.8 -fold, respectively. Treatment of HepG 2 cells in culture with mildly oxidized LDL (but not native LDL) resulted in reduced mRNA levels for PON (3.0-fold decrease) and increased mRNA levels for apoJ (2.0-fold increase). In normolipidemic patients with angiographically documented coronary artery disease who did not have diabetes and were not on lipid-lowering medication $(n=14)$, the total cholesterol/HDL cholesterol ratio was $3.1 \pm 0.9$ as compared to $2.9 \pm 0.4$ in the controls $(n=$ 19). This difference was not statistically significant. In contrast, the apoJ/PON ratio was $3.0 \pm 0.4$ in the patients compared to $0.72 \pm 0.2$ in the controls $(P<0.009)$. In a subset of these normolipidemic patients $(n=5)$, the PON activity was low $(48 \pm 6.6$ versus $98 \pm 17 \mathrm{U} / \mathrm{ml}$ for controls; $P<$ 0.009), despite similar normal HDL levels, and the HDL from these patients failed to protect against LDL oxidation in co-cultures of human artery wall cells. We conclude that: (a) mildly oxidized LDL can induce an increased apoJ/PON ratio, and $(b)$ the apoJ/PON ratio may prove to be a better
\end{abstract}

Address correspondence to Mohamad Navab, Ph.D., Cardiology, 47123 CHS, UCLA Med School, Box 951679, Los Angeles, CA 900951679. Phone: 310-206-2678; FAX: 310-206-2822; E-mail: mnavab@ medicine.medsch.ucla.edu

Received for publication 17 October 1996 and accepted in revised form 6 February 1997.

J. Clin. Invest.

(C) The American Society for Clinical Investigation, Inc.

0021-9738/97/04/2005/15 \$2.00

Volume 99, Number 8, April 1997, 2005-2019 predictor of atherosclerosis than the total cholesterol/HDL cholesterol ratio. (J. Clin. Invest. 1997. 99:2005-2019.) Key words: atherosclerosis • paraoxonase - apoJ • risk factor • $\mathrm{HDL} \cdot \mathrm{LDL} \cdot$ phospholipid • inflammatory reaction

\section{Introduction}

We have previously reported that high-density lipoprotein (HDL)-associated enzymes can protect low density lipoproteins (LDL) against oxidation by aortic wall cells (1-5). We also reported that during an acute phase response these enzymes were depleted, and there was an increase of serum amyloid A (SAA) ${ }^{1}$ and ceruloplasmin in the acute phase HDL (3). The resulting HDL was thus converted from an antiinflammatory molecule to a proinflammatory molecule during the acute phase response in both rabbits and humans (3). In other studies, we reported that mice genetically susceptible to fatty streak lesions (C57BL/6J [BL/6]), but not genetically resistant mice $(\mathrm{C} 3 \mathrm{H} / \mathrm{HeJ}[\mathrm{C} 3 \mathrm{H}])$, when placed on an atherogenic diet, demonstrated a decrease in their HDL paraoxonase (PON) activity, and a concomitant loss of the HDL's ability to protect against LDL oxidation by artery wall cells (4). In these studies, we demonstrated that aortic fatty streak lesion formation was genetically linked to the expression of PON mRNA, and that the link was not with the PON gene, but with a transacting factor controlling PON mRNA levels (4). In the current studies, we report that apolipoprotein $\mathrm{J}$ (apoJ) is increased in the BL/6 (but not the $\mathrm{C} 3 \mathrm{H}$ mice) on an atherogenic diet. We further show that in the $\mathrm{BL} / 6$ mice (but not in the $\mathrm{C} 3 \mathrm{H}$ mice) there was a marked decline in PON activity following $8 \mathrm{wk}$ on the atherogenic diet. Moreover, we show that on a chow diet, apoJ was elevated, and PON was reduced in apolipoprotein E knockout mice, a model for advanced atherosclerosis. When LDL receptor knockout mice were fed an atherogenic diet, their apoJ/PON ratios increased by approximately 100 -fold. In rabbits, we demonstrate that apoJ was induced by both an acute phase response, and by cholesterol feeding. In in vitro studies, we demonstrate that mildly oxidized LDL produced by human aortic wall cell co-cultures caused an increase in mRNA levels for apoJ, and a decrease in mRNA levels for PON in HepG 2 cells. Within 24 h of injection of this mildly oxidized LDL into BL/6 mice on a chow diet, there was an increase in apoJ and a decrease in PON that was not seen with the injection of native LDL or by incubating the mouse plasma

1. Abbreviations used in this paper: $\mathrm{BL} / 6, \mathrm{C} 57 \mathrm{BL} / 6 \mathrm{~J}$ mice; $\mathrm{C} 3 \mathrm{H}, \mathrm{C} 3 \mathrm{H} /$ HeJ mice; CM-LDL, co-culture modified LDL; FPLC, fast-performance liquid chromatography; HAEC, human aortic endothelial cells; HASMC, human aortic smooth muscle cells; HPF, high-power field, OxPAPC, oxidized 1-palmitoyl-2-arachidonoyl-sn-glycero-3-phosphorylcholine; PON, paraoxonase; SAA, serum amyloid A. 
with the mildly oxidized LDL. In humans with angiographically documented coronary atherosclerosis that had normal total cholesterol/HDL cholesterol ratios, normal LDL levels, and normal triglyceride levels, there were no increases in SAA or in ceruloplasmin levels. Moreover, apoJ levels were elevated in these patients, and PON activity tended to be reduced, resulting in a significant increase in the apoJ/PON ratio.

\section{Methods}

Materials. Tissue culture materials and other reagents were obtained from sources previously described $(5,1-3)$. Authentic 1-palmitoyl2-arachidonoyl-sn-glycero-3-phosphorylcholine (PAPC) was obtained from Sigma Chemical Co. (Saint Louis, MO) or from Avanti Polar Lipids (Alabaster, AL) Purified human apoJ and a monoclonal antibody to human apoJ were obtained from Quidel (San Diego, CA).

Co-cultures. Multilayer co-cultures of human aortic endothelial cells (HAEC) and smooth muscle cells (HASMC) were formed as previously described (5). The artery wall cells were isolated from aortic specimens obtained from donor hearts. HASMC were seeded at a confluent density of $1 \times 10^{5}$ cells $/ \mathrm{cm}^{2}$, and were cultured for $3 \mathrm{~d}$, at which time they had covered the entire surface of the well, and had produced a substantial amount of extracellular matrix. HAEC were subsequently seeded at $2 \times 10^{5}$ cells $/ \mathrm{cm}^{2}$ and were allowed to grow, forming a complete monolayer of confluent EC in $2 \mathrm{~d}$.

Lipoproteins. LDL ( $d=1.019-1.063 \mathrm{~g} / \mathrm{ml})$, HDL $(d=1.069-1.210$ $\mathrm{g} / \mathrm{ml}$ ), and lipoprotein-deficient serum (LPDS, $d>1.21 \mathrm{~g} / \mathrm{ml}$ ) were isolated from the sera of normal blood donors, or plasma from mice strains on different diets, by sequential density ultracentrifugation (6) in the absence of EDTA to aviod inactivation of PON. In addition, HDL-containing fractions were isolated by gel filtration (fast-performance liquid chromatography, FPLC) (7). In the experiments described, lipoprotein concentrations are expressed according to their protein content. The characterization of isolated HDL fractions from mouse plasma has been previously reported (7).

Lipid hydroperoxide assay. Lipid hydroperoxide levels were measured using the method of Auerbach et al. (8). This method measures 13(S)HPODE (the oxidation product of 15-lipoxygenase action on linoleic acid), which oxidizes leucomethylene blue to methylene blue in the presence of hemoglobin (quantitated at $660 \mathrm{~nm}$ ).

Mice and diets. Mice were purchased from the Jackson Laboratory (Bar Harbor, ME). All animals were female (4-6 mo of age) at the time of the experiments. The control (chow) diet was Purina Chow (Ralston-Purina Co., St. Louis, MO) containing 4\% fat. Two different high-fat atherogenic diets for the mice were obtained from Harlan Teklad (Madison, WI). The diet with higher cholesterol content (TD 90221) contained $1.25 \%$ cholesterol, $15.75 \%$ fat, and $0.5 \%$ sodium cholate. This diet was used for $\mathrm{BL} / 6$ and $\mathrm{C} 3 \mathrm{H}$ mice. The atherogenic diet with lower cholesterol content was 88137, and contained $0.15 \%$ cholesterol, and $12.8 \%$ milk fat. This diet was used for the LDL receptor knockout mice. Blood samples were collected from retroorbital sinus using heparin as an anticoagulant $(2.5 \mathrm{U} / \mathrm{ml}$ blood $)$ after 8 or $9 \mathrm{wk}$ on the diets. The sampling was carried out under mild IsoForin anesthesia, adhering to the regulations set forth by the University of California Animal Research Committee. For hepatic mRNA determinations, the mice were killed, and their livers were removed and quick-frozen on dry ice.

Monocyte transmigration assay. Blood monocytes were isolated from a large pool of healthy donors by a modification of the Recalde procedure (9). Monocyte transmigration was determined using the protocol described previously (5). Briefly, co-cultures of HAEC and HASMC containing 10\% LPDS were treated with freshly isolated human LDL at $250-350 \mu \mathrm{g} / \mathrm{ml}$ in the absence or presence of various test compounds for $18 \mathrm{~h}$. The culture supernatants, containing cell-modified mildly oxidized LDL (CM-LDL), were subsequently transferred to untreated co-cultures, and were incubated for $6 \mathrm{~h}$. Monocytes were labeled with the fluorescent probe DiI (1,1'-dioctadecyl-3,3,3',3'-tet- ramethyl-indo-carbocyanine perchlorate) at $4^{\circ} \mathrm{C}$ for $10 \mathrm{~min}$, and were then washed. The cell pellet was resuspended in medium 199 at the desired monocyte density. At the end of the 6-h incubation of co-cultures, labeled monocytes were added at $2.5 \times 10^{5} \mathrm{cells} / \mathrm{cm}^{2}$, and incubated for $30 \mathrm{~min}$ at $37^{\circ} \mathrm{C}$. The medium containing nonadherent cells was then removed, and the cell layers were washed at $37^{\circ} \mathrm{C}$ to remove the loosely adherent cells on top of the endothelial monolayer. The co-cultures were fixed and mounted, and subendothelial monocytes were enumerated under 625 -fold magnification. In pilot experiments the supernatants from co-cultures were tested for chemotactic activity using a standard Neuroprobe chamber.

ApoJ ELISA. Highly specific and sensitive ELISAs were developed for determining the levels of apoJ in human subjects and in mice plasma samples. Microtiter plates (Nunc) were coated with human plasma diluted 1:8,000 in PBS and 0.2\% Tween, and were incubated at $4^{\circ} \mathrm{C}$ for $18 \mathrm{~h}$. The plates were washed three times with PBS, with 1.0-min soaks in between. Monoclonal antibody to purified human apoJ (Quidel) diluted at 1:8,000 was then added, and plates were incubated at room temperature for $60 \mathrm{~min}$. The plates were then washed three times with PBS, with 1.0-min soaks in between. The secondary antibody, a sheep anti-mouse HRP-conjugated antibody (Amersham Corp., Arlington Heights, IL) diluted at 1:6,000 was then added, and plates were incubated at room temperature for $60 \mathrm{~min}$. The plates were washed three times with PBS, with 1.0-min soaks in between. The chromogenic substrate DAB (Sigma) was subsequently added, plates were read in a plate reader, and data was analyzed by SoftMax application (Molecular Dynamics, Sunnyvale, CA). Western blot analyses using the monoclonal antibody to purified human apoJ demonstrated the presence of a single 34-kD band (10) (data not shown). The ELISA for determining murine plasma apoJ level was essentially similar to that for human apoJ except for diluting the mouse plasma by 1:7000, and using a 1:1000 dilution of an anti rat apoJ (kindly provided by Dr. Michael D. Griswold, Department of Biochemistry and Biophysics, Washington State University, Pullman, WA). Using this antibody in Western blot analyses, only a nonreduced $67-\mathrm{kD}$ band and a pair of reduced doublet bands of 34 and 36 $\mathrm{kD}$ for murine apoJ (11) were observed (see Fig. $4 D$ ).

PON activity. HDL and other samples were assayed for PON activity using paraoxon as substrate (12). The cuvette contained $1.0 \mathrm{mM}$ paraoxon in $20 \mathrm{mM}$ Tris $/ \mathrm{HCl}, \mathrm{pH}$ 8.0. The reaction was initiated by the addition of the plasma or lipoprotein sample, and the increase in the absorbance at $405 \mathrm{~nm}$ was recorded over a 90 -s period. Blanks were included to correct for the spontaneous hydrolysis of paraoxon. Enzymatic activity was calculated from the molar extinction coefficient $1310 \mathrm{M}^{-1} \mathrm{~cm}^{-1}$. A unit of PON activity is defined as $1 \mathrm{nmol}$ of 4-nitrophenol formed per min under the above assay conditions (12). In samples from the mice strains on the chow or the atherogenic diet, or after injections of oxidized lipids, the contribution of non HDL fractions of serum to paraoxon hydrolysis was consistantly between 2.1 and $4.5 \%$. Similarly, in human plasma from patients and controls, plasma fractions contributed to paraoxon hydrolysis by 2.7 to $5.2 \%$. For purified PON standard solutions, PON isoforms were isolated as described previously (12).

RNA hybridization. Total RNA from 100-200 mg of the livers of mice on chow or on an atherogenic diet was extracted with TRIzol reagent (GIBCO BRL, Gaithersburg, MD). Poly(A)+ RNA was isolated from $125 \mu \mathrm{g}$ of total RNA by oligo-dT chromatography (Oligotex mRNA kit; Qiagen, Inc., Chatsworth, CA). RNA gel blots were prepared by loading $1.0 \mu \mathrm{g}$ of poly(A) + RNA or $20 \mu \mathrm{g}$ of total RNA per lane, fractionated on denaturing $1.2 \%$ agarose gels, and subsequently transferred to nylon. The blots were hybridized with an antisense 900 base apoJ cRNA probe transcribed (Riboprobe kit, Promega, WI) from a truncated apoJ cDNA insert in BSSK + which was kindly provided by Dr. Irina Rozovsky (University of Southern California Neurogerantology). For PON mRNA detection, a probe with the sequence of 5' attatcttcATCTGTGAATGTGCTAATCCCATGAGGGTTAAA TG-3' (4) was used.

Hep 2 cell culture. HepG2 cells were cultured in Iscove's Modi- 
fied Eagle medium containing $10 \%$ FBS to a confluency of $85 \%$. At the time of experiment, the cells were washed and transferred to Ham's F-10 medium containing 10\% LPDS for $1 \mathrm{~h}$ to equilibrate the cells. The cells were subsequently washed, and fresh media containing the experimental additions was added. Alternatively, for Northern blot analyses of RNA, $5 \mu \mathrm{g}$ of total RNA was electrophoresed through formaldehyde $1.5 \%$ agarose gels, and was transferred to nylon membranes. The blots were hybridized with ${ }^{32} \mathrm{P}$-labeled probes at $65^{\circ} \mathrm{C}$ overnight in a solution containing $0.5 \mathrm{M}$ sodium phosphate, $1 \mathrm{mM}$ EDTA, $1 \%$ BSA, and 7\% SDS, pH 7.0. The blots were then washed in $0.1 \times \mathrm{SSC}, 0.1 \% \mathrm{SDS}$ at $65^{\circ} \mathrm{C}$ for $30 \mathrm{~min}$. Blots were dried, and autoradiography was performed. The autoradiographs were quantitated by densitometric scanning.

Rabbit plasma and tissues. New Zealand white male rabbits, 2-3 $\mathrm{kg}$ each were either fed a chow diet alone, a chow diet supplemented with $2 \%(\mathrm{wt} / \mathrm{wt})$ cholesterol and $10 \%(\mathrm{wt} / \mathrm{wt})$ corn oil, or were injected with croton oil based on the protocol of Cabana et al. (13) to induce an acute phase response. A $1 \%(\mathrm{vol} / \mathrm{vol})$ emulsion of croton oil (Sigma) in mineral oil (Sigma) was prepared in a sterile manner, and $2.0 \mathrm{ml}$ per $\mathrm{kg}$ was injected into five sites in the large lower back muscle. Blood samples were drawn from the central ear artery before death under pentobarbital anesthesia, and livers were removed and quick-frozen on dry ice. Samples were taken from rabbits during the acute phase $48 \mathrm{~h}$ after injection of croton oil.

Western blot analysis. $1 \mu \mathrm{l}$ of plasma was subjected to sodium dodecyl sulfate polyacrylamide gel electrophoresis (SDS-PAGE) according to the procedure of Laemmli (14) using 4-20\% gels, and was applied to Hybond ${ }^{\mathrm{TM}}$ ECL Nitrocellulose membrane (Amersham) in Tris-buffered saline. Chemiluminescent detection of proteins was carried out and analyzed using the ECL Western blotting kit (Amersham) according to the manufacturer's suggested protocol. The primary antibody used was goat anti-human apoJ or rabbit anti-rat apoJ. The secondary antibody used was horseradish peroxidase-conjugated anti-goat IgG (Amersham).

Quantitation of gene expression. Total RNA was extracted from the Hep- $\mathrm{G}_{2}$ cells and rabbit liver homogenates according to the technique of Chomczyski and Sacchi (15). Northern blot analysis was used to quantitate the mRNA levels of apoJ and PON. For each sam- ple, $15 \mu \mathrm{g}$ of RNA were electrophoresed on formaldehyde/1\% agarose gels, and were transferred to $20 \times$ SSC equilibrated Hybond $\mathrm{ECL}^{\mathrm{IM}}$ nitrocellulose membrane. Membranes were hybridized with the appropriate probe following UV cross-linking, and were washed at a high stringency $\left(65^{\circ} \mathrm{C}, 0.1 \times \mathrm{SSC}\right)$. The apoJ probe had a sequence of 5' CAGTCCACAGACAAGATCTCCTGGCACTTTTCACACTGG C 3'. The PON probe had a sequence referred to under RNA hybridization. The blots were also hybridized using a cDNA probe for $18 \mathrm{~S}$ ribosomal RNA to normalize the quantities of RNA loaded into the gel lanes.

Patient studies. After signing a written consent (approved by the University of California Human Subject Committee), subjects undergoing coronary angiography at UCLA donated a sample of blood collected in heparinized tubes. Plasma lipid profile was determined, and a subgroup of 14 individuals ( 9 males and 5 females) with normal plasma lipid levels were selected from a total of 250 cases. The selection criteria were set to include patients with total cholesterol $<200$ $\mathrm{mg} / \mathrm{dl}$, triglycerides $<150 \mathrm{mg} / \mathrm{dl}$, LDL cholesterol $<130 \mathrm{mg} / \mathrm{dl}$, and HDL cholesterol $>40 \mathrm{mg} / \mathrm{dl}$ for males and $>50 \mathrm{mg} / \mathrm{dl}$ for females. The selected patients were diagnosed as having documented coronary atherosclerosis, were not on lipid-lowering medications, and did not have diabetes. Subjects on niacin or estrogen replacement therapy were not included. For controls, blood samples were also obtained from age- and sex-matched consented normal subjects (11 males and 8 females). The control subjects were selected from a large pool of normal donors ( $n=325$, consisting of mostly younger individuals) in our program's core facility. They were not on medications and did not have known inflammatory conditions. Plasma total cholesterol, HDL, LDL, and triglycerides were determined in addition to the clinical lab system by using kits (Sigma) and as previously described (16).

Other procedures. The protein content of cells and lipoproteins was measured using a microtiter plate assay (17) based on the method of Lowry et al. (18). Levels of monocyte chemotactic protein 1 (MCP-1) were determined using a kit from Antigenix America (Tarrytown, $\mathrm{NY}$ ), and as described previously (5). Oxidized 1-palmitoyl-2-arachidonyl-sn-glycero-3-phosphorylcholine PAPC (Ox-PAPC) was produced by exposure of PAPC to air in a laminar flow hood at room
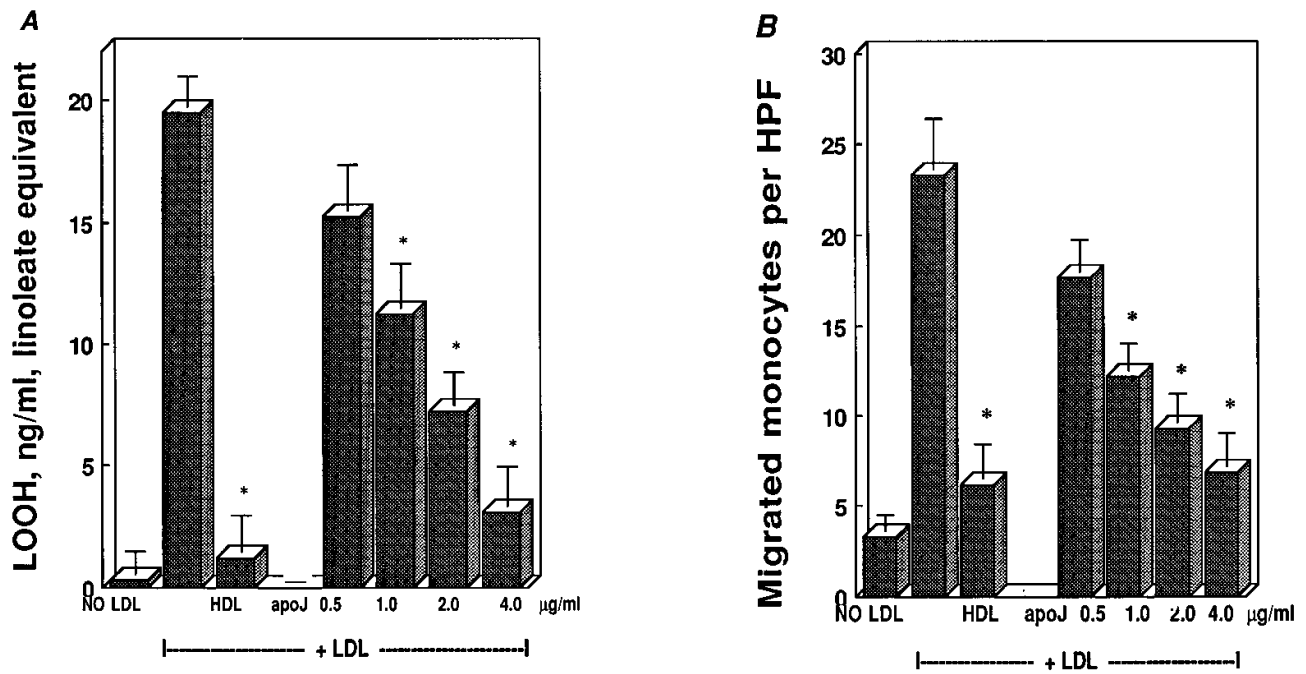

Figure 1. (A) Effect of incubation of co-cultures with apoJ on LDL-induced monocyte transmigration. LDL was incubated together with purified human apoJ in co-cultures of human aortic endothelial cells and smooth muscle cells. The co-cultures were treated with medium alone, or with freshly isolated LDL at $350 \mu \mathrm{g} / \mathrm{ml}$. To some wells was added LDL together with HDL or with apoJ at the indicated concentrations. After $18 \mathrm{~h}$ of incubation, conditioned medium was removed, and was assayed for lipid hydroperoxide levels as described in Methods. Data represents mean \pm SD of values for quadruple co-cultures in each treatment. Asterisks indicate significant difference at the level of $P<0.01$, between the apoJ containing wells and those with LDL alone. $(B)$ Effect on monocyte transmigration. After $18 \mathrm{~h}$ of incubation with LDL alone or LDL plus HDL or apoJ, conditioned medium was transferred to another set of target co-cultures. The medium was removed from the target cocultures after $6 \mathrm{~h}$ of incubation and a suspension of DiIlabeled monocytes was added at $2.5 \times 10^{5}$ cells $/ \mathrm{cm}^{2}$ to the endothelial side of the co-cultures. The cocultures were returned to the incubator and maintained for $30 \mathrm{~min}$. The medium was then removed, co-cultures were washed and mounted, and subendothelial monocytes were enumerated under $625 \times$ total magnification. Values shown are mean \pm SD of the number of monocytes in 36 fields in 12 co-cultures for each treatment. Asterisks indicate significant difference at the level of $P<0.01$, between the wells containing LDL or LDL plus apoJ. 
temperature for $48 \mathrm{~h}$ (2). Ox-PAPC preparations were routinely shown to contain bioactive oxidized species by mass spectrometry as described previously (2). Mildly oxidized LDL was prepared by incubating LDL $(1.0 \mathrm{mg} / \mathrm{ml})$ in co-cultures of artery wall cells in M199 containing $10 \%$ LPDS $(1,2)$ and was referred to as co-culture-modified LDL, or CM-LDL. Following the incubation of LDL with the cocultures, CM-LDL was isolated by FPLC. CM-LDL preparations were routinely checked for the ability to induce monocyte-endothelial interactions in the co-culture system before injection into the mice. For injection into mice, $100 \mu \mathrm{g}$ Ox-PAPC or CM-LDL in $100 \mu \mathrm{l}$ saline was administered through the tail vein. Serum amyloid A levels were determined on human samples using a commercially available kit (Bio Genics, Camarillo, CA). Ceruloplasmin levels were determined as previously described (3).

\section{Results}

ApoJ prevents $L D L$ oxidation by artery wall cells but has no effect once the LDL has been oxidized by the artery wall cells

As shown in Fig. 1, coincubation of LDL with purified apoJ revealed a dose-dependent inhibition of LDL-induced lipid hydroperoxide formation $(A)$ and monocyte transmigration $(B)$. ApoJ treatment had an effect on LDL-induced MCP-1 induc- tion in co-cultures (data not shown) that was highly similar to the effects on lipid hydroperoxide formation and monocyte migration. Preincubation of LDL or the artery wall cells in coculture with purified apoJ also prevented the formation of lipid hydroperoxides, induction of MCP-1, and monocyte transmigration in a dose-dependent manner (data not shown). This observation indicated that apoJ is capable of interfering with the interaction of the cells with LDL that is presumed to result in the seeding of LDL with cellular oxidized lipids, oxidation of LDL, and induction of MCP-1 (19-22). Whereas apoJ is capable of preventing LDL oxidation by artery wall cells in culture (unlike PON which is capable of completely abolishing the bioactivity of the already formed CM-LDL) (2), apoJ in a range of concentration of $0.5-5.0 \mu \mathrm{g} / \mathrm{ml} \mathrm{did}$ not reduce the bioactivity of the CM-LDL $(16.8 \pm 1.7$ monocytes per high-power field for CM-LDL vs. $15.3 \pm 1.2$ monocytes per high-power field for apoJ treated CM-LDL, data not shown).

\section{Studies in mice}

Plasma apoJ and PON vary inversely in lesion-prone but not in lesion-resistant mice fed an atherogenic diet. FPLC fractions of pooled plasma from BL/6 mice on an atherogenic diet con-
A
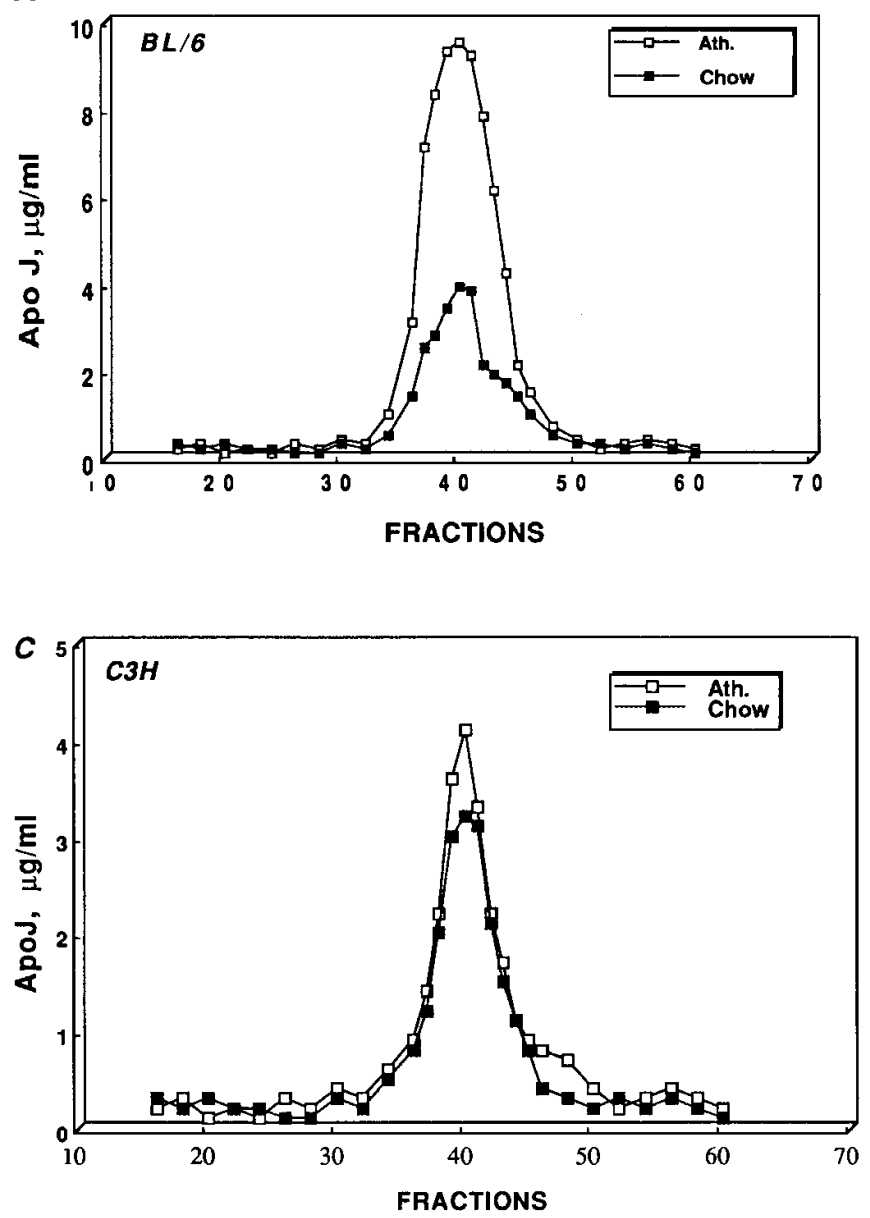

$\boldsymbol{B}$

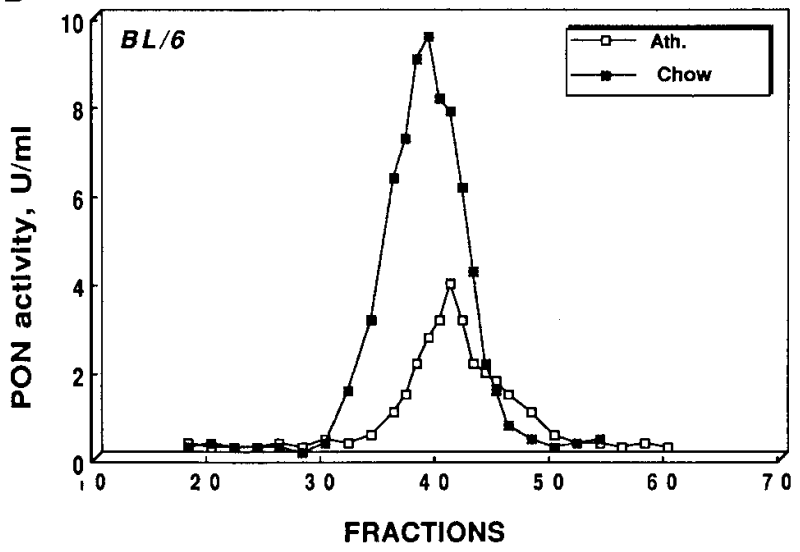

$D$

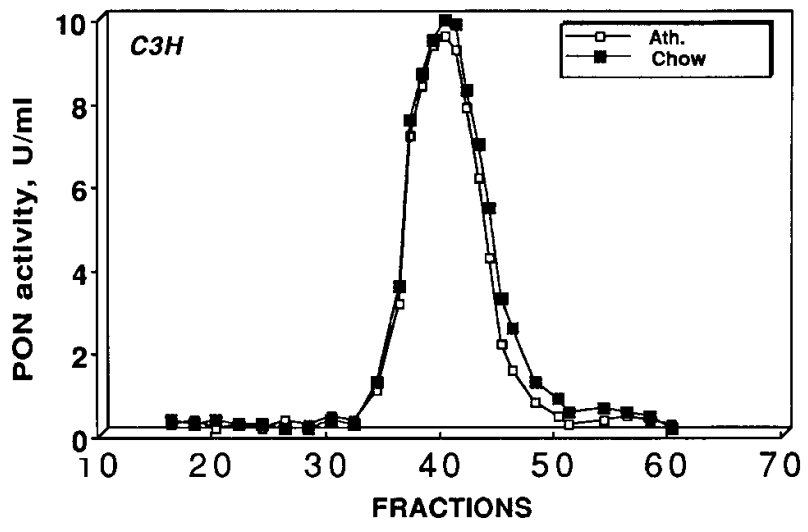

Figure 2. Plasma FPLC profiles for apoJ and PON for mice strains on the chow or an atherogenic diet. Groups of mice (6 each) from the atherosclerosis-susceptible strain $(\mathrm{BL} / 6)$ and the resistant strain $(\mathrm{C} 3 \mathrm{H})$ were maintained on the chow or on an atherogenic diet for 8 wk. Blood was collected from the retroorbital sinus under mild anesthesia, and plasma samples pooled and were fractionated by FPLC. ApoJ concentration $(A$ and $C$ for BL/6 and $\mathrm{C} 3 \mathrm{H}$ mice, respectively) and PON activity ( $B$ and $D$ for BL/6 and C3H mice, respectively) were determined in triplicates on each of the 1.0-ml fractions as described in Methods. 
A

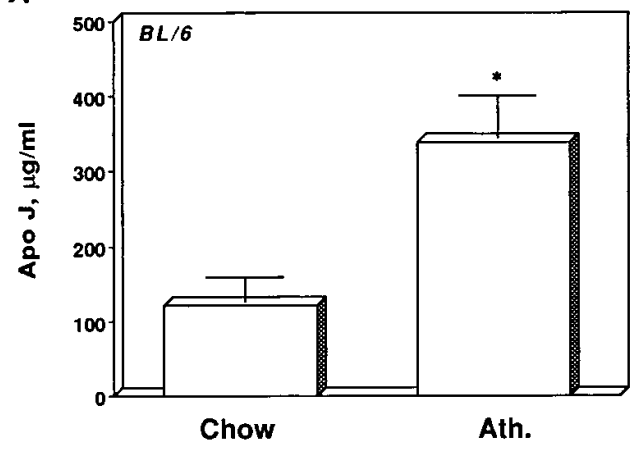

D

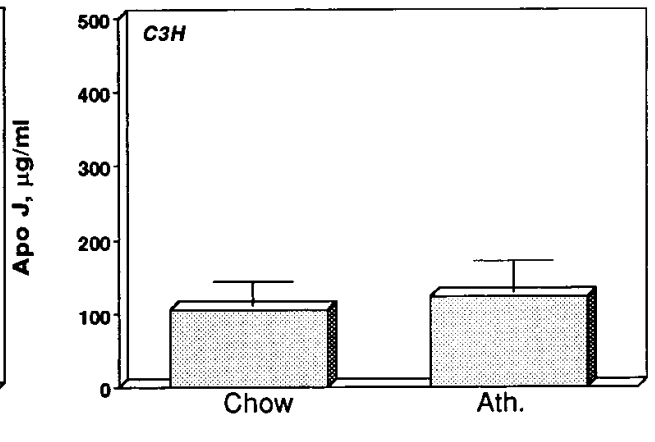

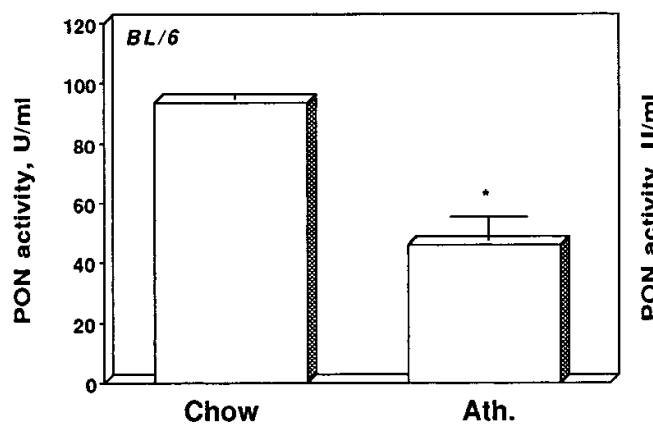

C

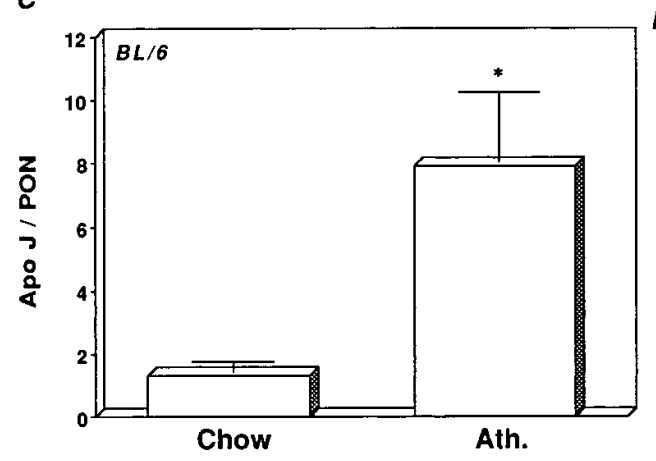

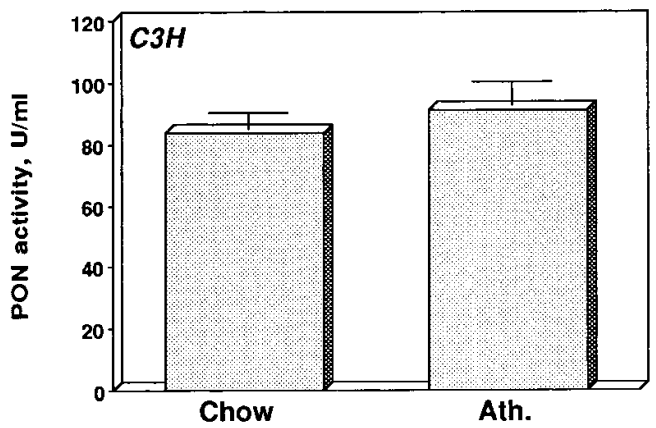

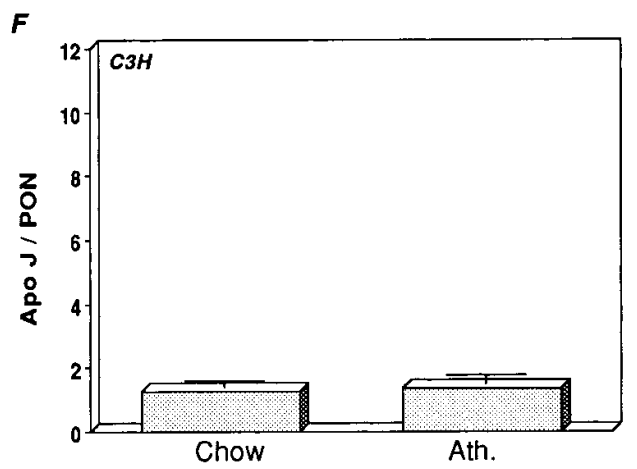

Figure 3. Plasma apoJ concentration and PON activity in mice strains on different diets. Groups of mice (5 each) from the $\mathrm{BL} / 6$ and the $\mathrm{C} 3 \mathrm{H}$ strains were maintained on the chow or on an atherogenic diet for $9 \mathrm{wk}$. Blood was collected and plasma pools of each group were analyzed for apoJ concentration $(A$ and $D$ for $\mathrm{BL} / 6$ and $\mathrm{C} 3 \mathrm{H}$ mice, respectively) and for PON activity ( $B$ and $E$ for BL/6 and $\mathrm{C} 3 \mathrm{H}$ mice, respectively) as described in Methods. The apoJ/PON ratios are shown in $C$ and $F$ for $\mathrm{BL} / 6$ and $\mathrm{C} 3 \mathrm{H}$ mice, respectively. Each value represents the mean \pm SD for results obtained for triplicate samples. Asterisks indicate significant differences at $P<0.01$. tained markedly increased levels of the murine homologue of apoJ (SGP-2) compared to FPLC fractions from BL/6 on the chow diet (Fig. $2 A$ ). PON activity in the FPLC fractions displayed a reverse profile compared with that for apoJ levels. Thus, BL/6 mice on the atherogenic diet had a significantly lower PON activity in the plasma fractions compared to the control mice on the chow diet (Fig. 2 B), a finding consistent with our previous observations (4). The $\mathrm{C} 3 \mathrm{H}$ plasma fractions, however, did not show a significant change in apoJ levels or PON activity when the mice were maintained on the atherogenic diet (Fig. 2, $C$ and $D$ ). Since the experiments described in Fig. 2 present the profile of apoJ and PON that is associated with HDL, total plasma levels were also determined. As shown in Fig. 3, the apoJ levels and the PON activity for unfractionated plasma of $\mathrm{BL} / 6$ on the atherogenic diet were $338 \pm 68 \mu \mathrm{g} / \mathrm{ml}$ and $43 \pm 6 \mathrm{U} / \mathrm{ml}$, respectively $(A$ and $B)$. This resulted in a high apoJ/PON ratio of $7.8 \pm 1.2$ as compared to $1.2 \pm 0.8$ for the chow controls $(P<0.001, C)$. Again, apoJ level and $\mathrm{PON}$ activity in unfractionated plasma from $\mathrm{C} 3 \mathrm{H}$ mice on the atherogenic diet were not different from those on the chow diet (Fig. 3, $D-F$ ). Evaluation of hepatic apoJ message levels revealed a similar pattern to that of plasma protein and activity (Fig. 4, $A-C$ ). There was a good agreement between the results from Northern analyses for apoJ using hepatic poly(A)+ RNA (Fig. 4, $A$ and $B$ ) or total RNA (Fig. $4 C$ ), demonstrating marked elevation of the hepatic apoJ message in the BL/6, but not the $\mathrm{C} 3 \mathrm{H}$ mice, on the atherogenic diet. ApoJ mRNA content of the liver from the BL/6 on atherogenic diet showed a $3.7 \pm .4$-fold increase over the message level for the chow controls $(P=0.017$, Fig. $4 C)$, the hepatic apoJ message levels for the $\mathrm{C} 3 \mathrm{H}$ on the atherogenic diet showed only a nonsignificant $(0.45 \%)$ increase compared with the values for the chow control $(P=0.26$, Fig. $2 B)$. Western blot analyses of apoJ protein in plasma revealed the presence of 4.8 -fold higher apoJ in plasma from $\mathrm{BL} / 6$ on the atherogenic diet compared to $\mathrm{BL} / 6$ on the chow or $\mathrm{C} 3 \mathrm{H}$ on either diet (Fig. $4 \mathrm{D}$ ). This increase was observed in both the monomeric ( 34 and $36 \mathrm{kD}$ bands) and the dimeric form ( $65 \mathrm{kD}$ band). The $65 \mathrm{kD}$ band has been 
$\boldsymbol{A}$

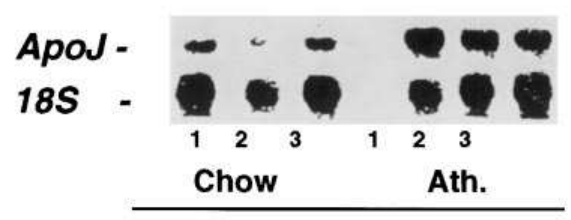

$B L / 6$

\section{$\boldsymbol{B}$}

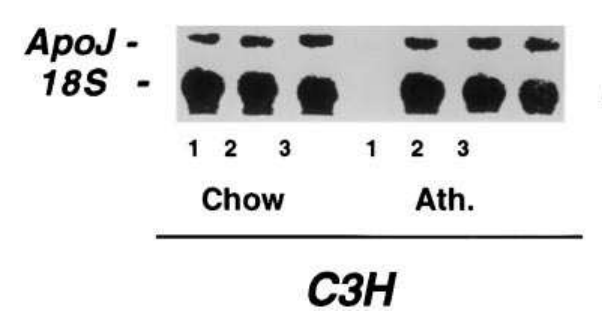

C

ApoJ -

$18 \mathrm{~S}$

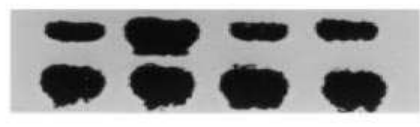

Chow Ath. Chow Ath.

\section{$B L / 6 \quad C 3 H$}

D

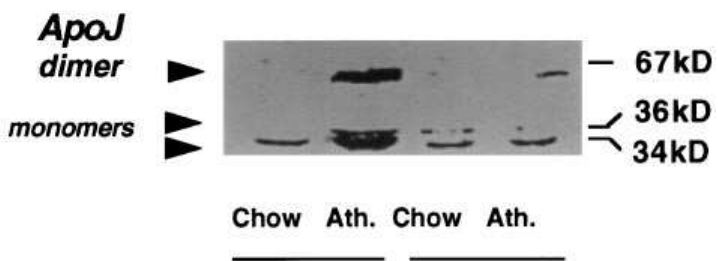

$B L / 6 \quad C 3 H$
Figure 4. Induction of apoJ in mice. Groups of mice (5 each) from the $\mathrm{BL} / 6$ and the $\mathrm{C} 3 \mathrm{H}$ strains were maintained on the chow or an atherogenic diet for $8 \mathrm{wk}$. $(A)$ and $(B)$ Three mice in each group were killed, livers were removed and snap-frozen, total RNA and poly(A) ${ }^{+}$RNA were isolated, and Northern blot analyses was carried out as detailed in Methods. $A$ demonstrates the hepatic apoJ message levels determined with $\operatorname{poly}(\mathrm{A})^{+}$ RNA from three individual BL/6 mice on the chow, and three on the atherogenic diet. $B$ demonstrates the results from $\mathrm{C} 3 \mathrm{H}$ mice determined with poly $(\mathrm{A})^{+}$ RNA. (C) Northern blot analyses was performed on total hepatic RNA from the mice on different diets using a cDNA probe as described in Methods. $(D)$ Blood was collected from five mice in each group from the retroorbital sinus, and Western blot analyses on the pooled plasma samples were carried out using a polyclonal anti-apoJ antibody as described in Methods.
A

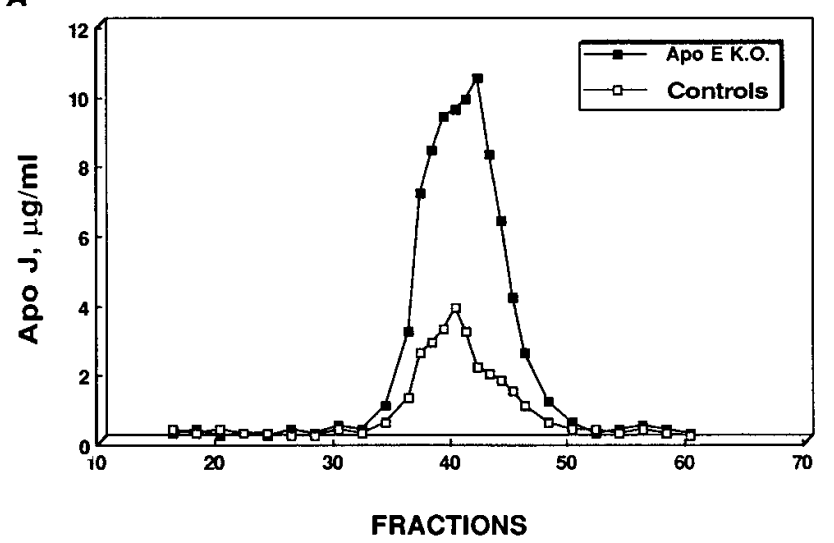

$B$

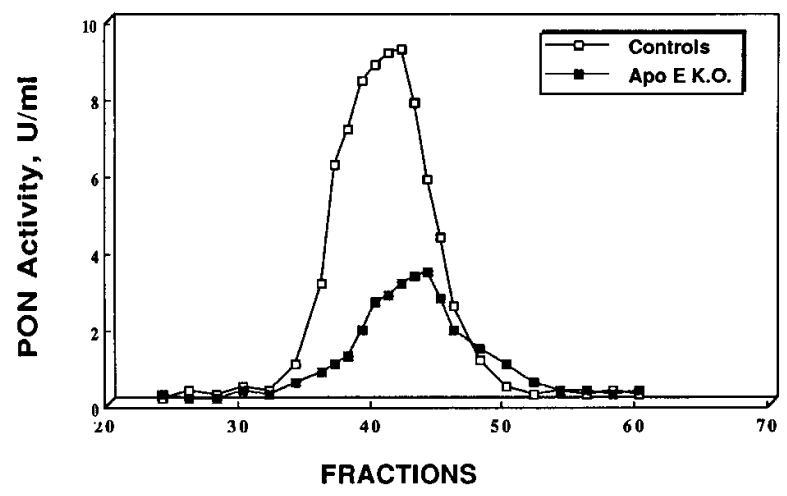

c

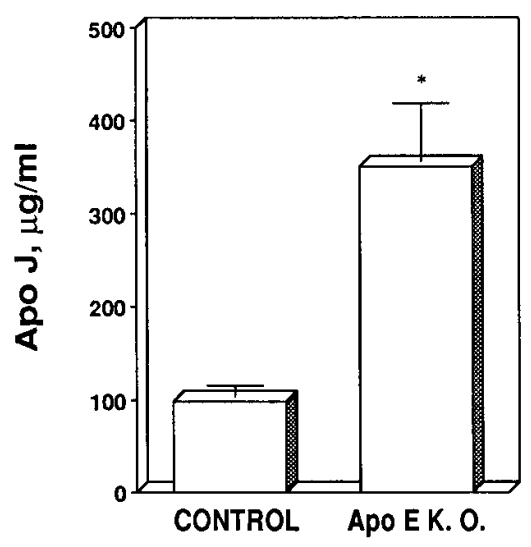

D

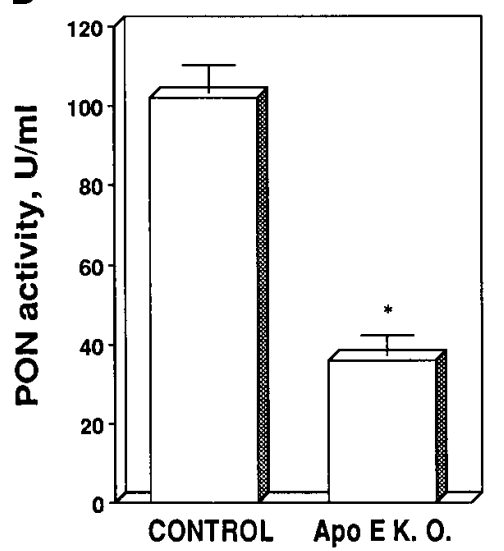

E

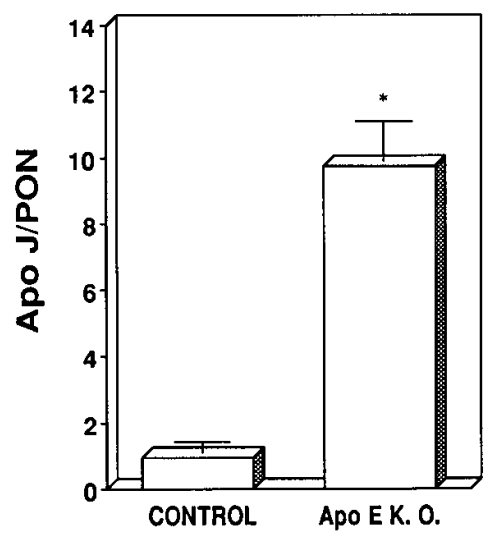

Figure 5. Distribution of PON and apoJ in apoE knockout mice. Heparinized pooled plasma samples (450 $\mu$ l) from five apoE knockout mice and five control litter mates were fractionated by FPLC as described in Methods. ApoJ concentration $(A)$ and PON activity $(B)$ were determined as described in Methods. Each point represents the mean for values obtained for triplicate samples. Additionally, unfractionated pooled plasma apoJ concentration and PON activity were determined as described in Methods $(C-E) . * P<0.01$. 


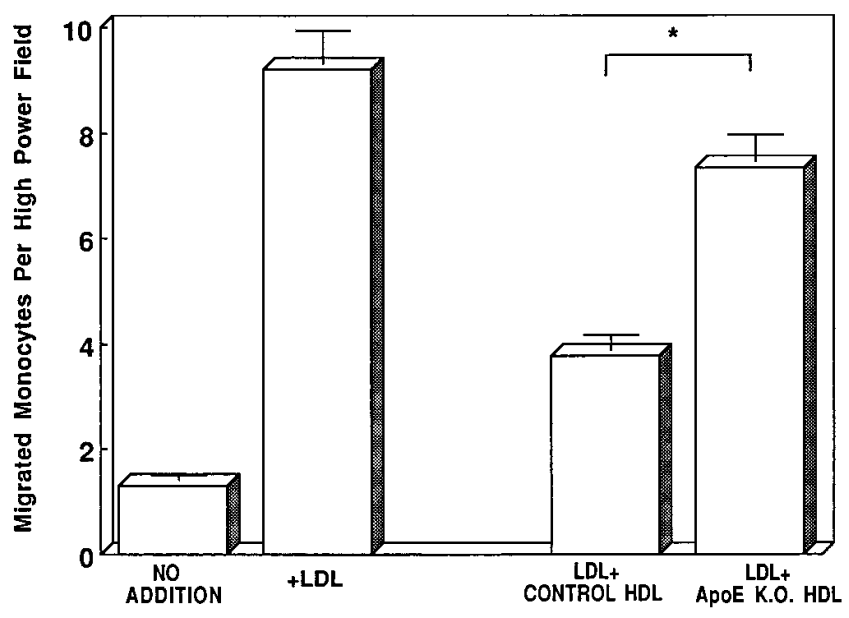

Figure 6. Prevention of LDL-induced monocyte transmigration by HDL. Aortic wall cell co-cultures were incubated with human LDL $(250 \mu \mathrm{g} / \mathrm{ml})$ for $18 \mathrm{~h}$ and monocyte transmigration assay was carried out as described in Fig. 1. To some of the co-cultures was added in addition, HDL $(350 \mu \mathrm{g} / \mathrm{ml})$ isolated from apoE knockout mice (designated as LDL+ApoE K.O. HDL), or from control littermates reported to be partially resistant to reducing conditions (10). These data with Western blot analyses confirm the data shown in Figs. 2 and 3, which were obtained using an ELISA.

Plasma apoJ increases and PON decreases in apoE knockout mice. A remarkable similarity was observed for apoJ levels and PON activity profiles when apoE knockout mice were evaluated. As shown in Fig. $5 A$, the apoJ levels for the apoE knockout mice were markedly higher in the FPLC fractions when compared to those for wild-type controls. PON activity, however, was remarkably lower in the apoE knockout mice in comparison with the values for the controls (Fig. $5 \mathrm{~B}$ ). The apoJ to PON ratio for apoE knockout mice whole plasma was $9.5 \pm 2.3$ compared to $0.9 \pm 1.7$ for the controls $(P=0.0012)$ (Fig. 5, C-E). Interestingly, at equal protein concentrations, the HDL from the apoE knockout mice had a markedly reduced capacity to inhibit LDL-induced monocyte transmigration in co-cultures of artery wall cells (Fig. 6).

(LDL+control HDL). Data represent mean \pm SD of values for quadruple co-cultures in each treatment. Asterisks indicate significance at the level of $P<0.01$.
$A$

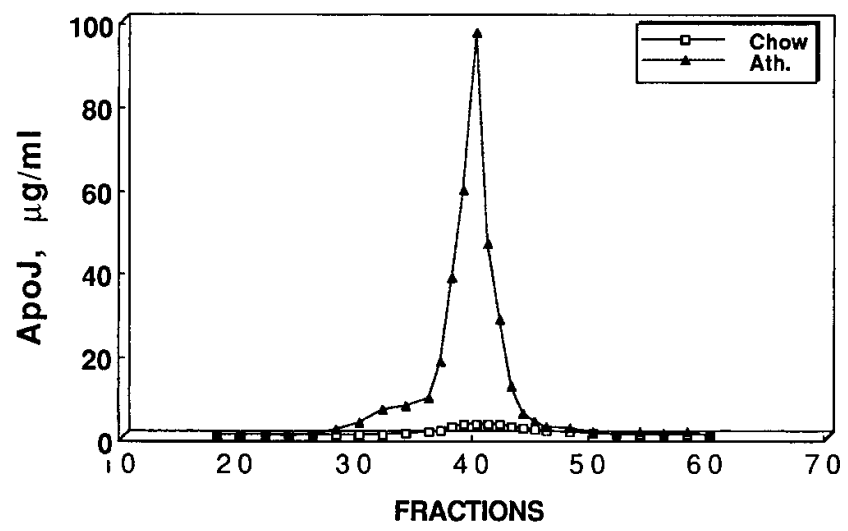

B

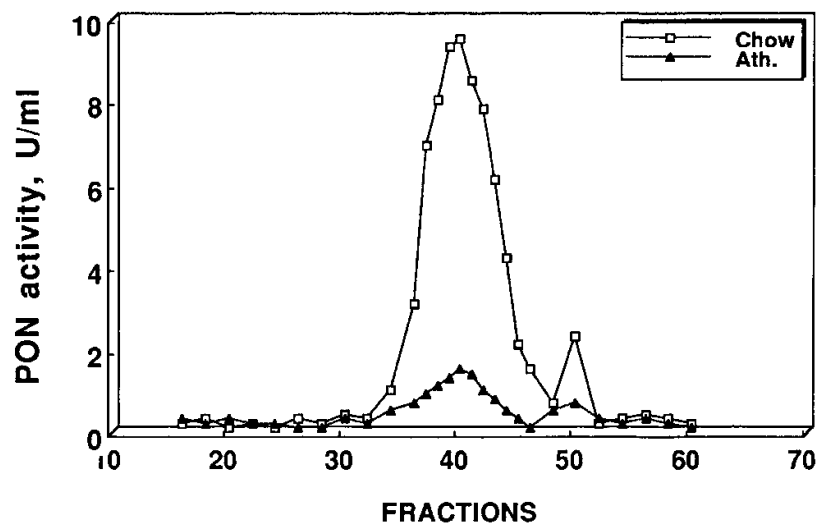

C

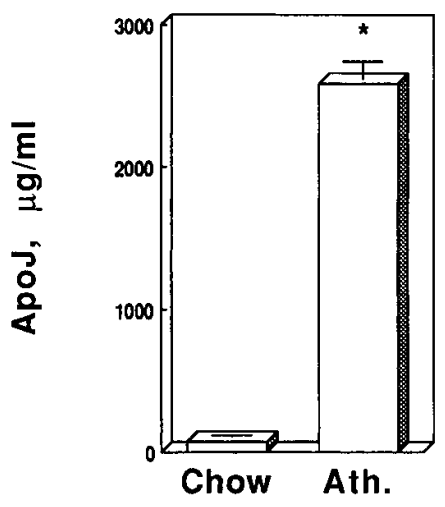

D

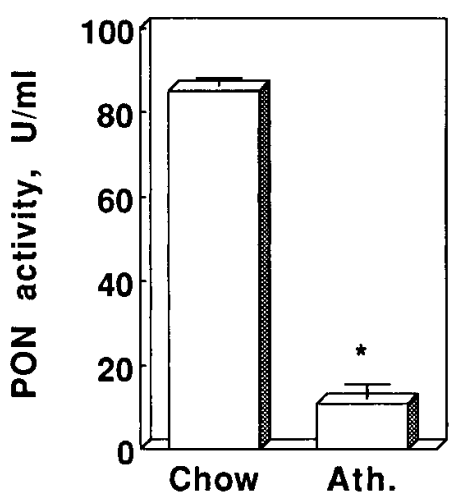

E

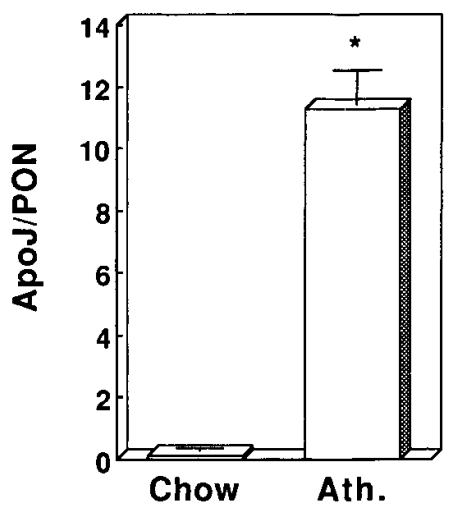

Figure 7. Plasma apoJ and PON in LDL receptor knockout mice. Heparinized pooled plasma samples (450 $\mu$ l) from five LDL receptor knockout mice placed on a $0.15 \%$ cholesterol-enriched high-fat (atherogenic) diet, and five on the chow diet, were fractionated by FPLC as described in Methods. ApoJ concentrations $(A)$ and PON activity $(B)$ were determined as described in Methods. Each point represents the mean for values obtained for triplicate samples. Additionally, unfractionated pooled plasma apoJ concentration and PON activity were determined as described in Methods $(C-E) . P<0.001$. 

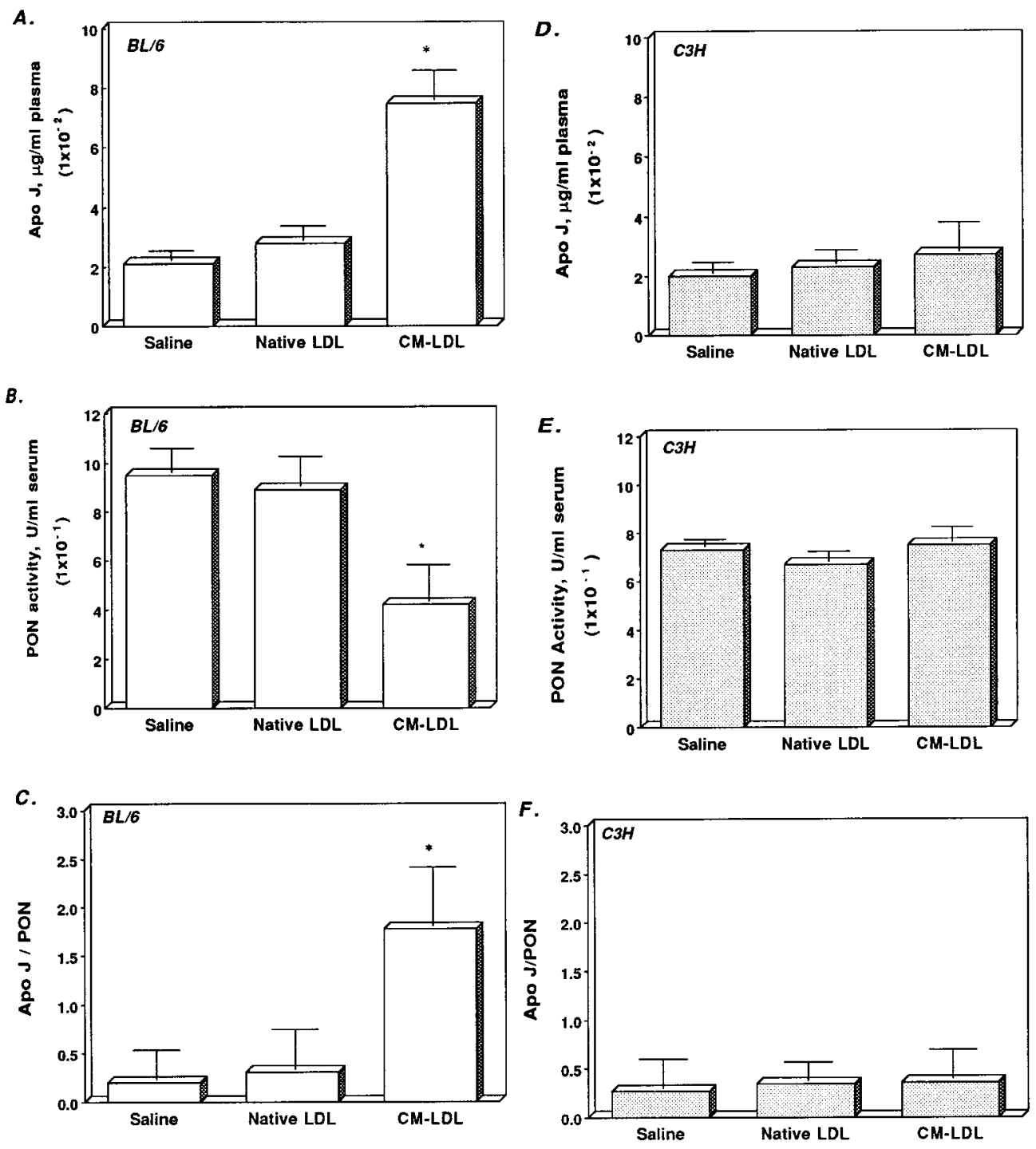

Figure 8. Effect of CM-LDL on plasma apoJ levels and PON activity. Three groups of five BL/6 mice $(A-C)$ and three groups of five $\mathrm{C} 3 \mathrm{H}$ mice $(D-F)$ maintained on the chow diet were injected with saline, with $100 \mu \mathrm{g}$ of native LDL in $100 \mu \mathrm{l}$ of saline or with LDL that had been previously modified by artery wall cells in co-cultures designated as CM-LDL. After $24 \mathrm{~h}$, blood samples were collected from the retroorbital sinus, and apoJ levels $(A$ and $D)$ and PON activity $(B$ and $E$ ) were determined. The values represent mean \pm SD of measurements on triplicate plasma samples. $C$ and $F$ compare the apoJ/PON ratios for the $\mathrm{BL} / 6$ and $\mathrm{C} 3 \mathrm{H}$ mice respectively. $* P<0.02$.

Dramatic increase of plasma apoJ and a marked reduction of PON activity in LDL receptor knockout mice on an atherogenic diet. As shown in Fig. 7, apoJ levels were dramatically increased $(A)$, and PON activity was remarkably lower $(B)$ in the plasma fractions from the LDL receptor knockout mice on the $0.15 \%$ cholesterol-enriched atherogenic diet when compared with the values on the chow diet. In the whole plasma also, apoJ levels were dramatically increased, and PON activity was markedly reduced when the LDL receptor knockout mice were placed on the atherogenic diet $(C$ and $D)$. Western blot analyses also demonstrated a dramatic increase in apoJ, and a marked increase in PON (data not shown). Consequently, the plasma apoJ to PON ratio for LDL receptor knockout mice on the atherogenic diet was over 100-fold higher on the atherogenic diet $(P<0.001)$ (Fig. $7 E)$.

$C M-L D L$ injection increases apoJ levels and decreases $P O N$ activity in BL/6 mice, but not in $\mathrm{C} 3 \mathrm{H}$ mice. As shown in Fig. $8 A$, injection of CM-LDL (but not native LDL) into the $\mathrm{BL} / 6$ mice on the chow diet resulted in a significant increase (3.6-fold, $P<0.01)$ in plasma apoJ levels, while it produced a $58 \%$ reduction in serum PON activity $(P<0.01)$ (Fig. $8 B$ ), and resulted in an increased apoJ/PON ratio of 1.8 compared to 0.3 and 0.4 for the mice injected with saline or native LDL, respectively (Fig. $8 \mathrm{C}$ ). This effect of CM-LDL on reduction of PON activity was likely not due to inactivation of PON in mouse plasma HDL, since incubation of native HDL (at 100 $\mu \mathrm{g} / \mathrm{ml}$ ) with the CM-LDL (at $100 \mu \mathrm{g} / \mathrm{ml}$ ) in vitro did not reduce the PON activity in HDL $(2.3 \pm 0.3 \mathrm{U} / \mathrm{mg}$ protein for sham-treated HDL vs. $2.1 \pm 0.4 \mathrm{U} / \mathrm{mg}$ protein for CM-LDL treated HDL, data not shown). In the $\mathrm{C} 3 \mathrm{H}$ mice, however, there were no significant changes in the plasma apoJ levels or PON activity upon the injection of CM-LDL (Fig. 8, $D-F$ ). In other experiments, PAPC or Ox-PAPC were injected into the $\mathrm{BL} / 6$ and $\mathrm{C} 3 \mathrm{H}$ mice, and plasma apoJ levels and PON activity were determined $24 \mathrm{~h}$ after the injections. Results similar to those obtained with the injection of native LDL and CM-LDL were obtained (Fig. 9, $A-F$ ). The changes in apoJ levels and PON activity were highly significant, and produced a 5.9-fold increase in the apoJ/PON ratio in the BL/6 (Fig. 9 C) with no significant changes in this ratio for the resistant $\mathrm{C} 3 \mathrm{H}$ mice (Fig. $9 F$ ).

\section{Studies in rabbits}

Fig. $10 A$ shows the induction of apoJ message in rabbit liver 
$\boldsymbol{A}$

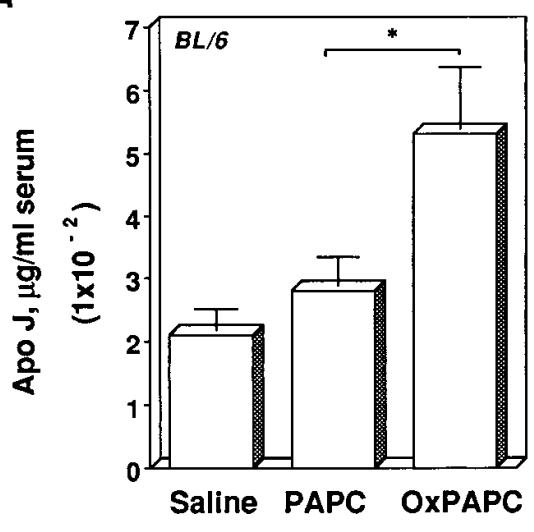

B

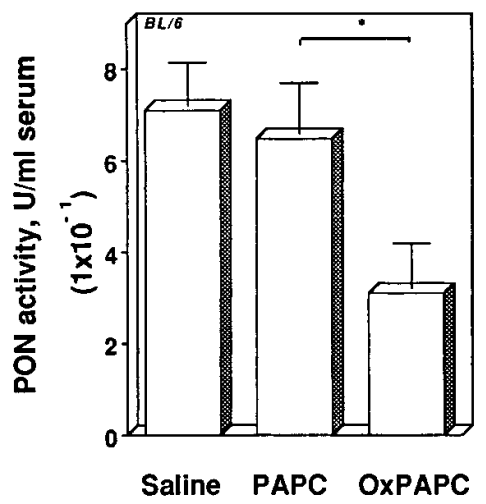

C

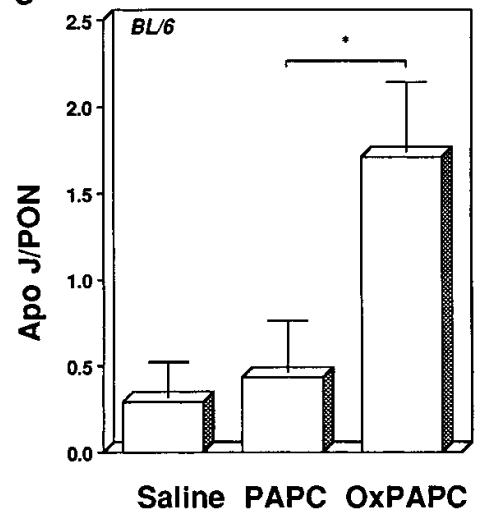

$\boldsymbol{D}$

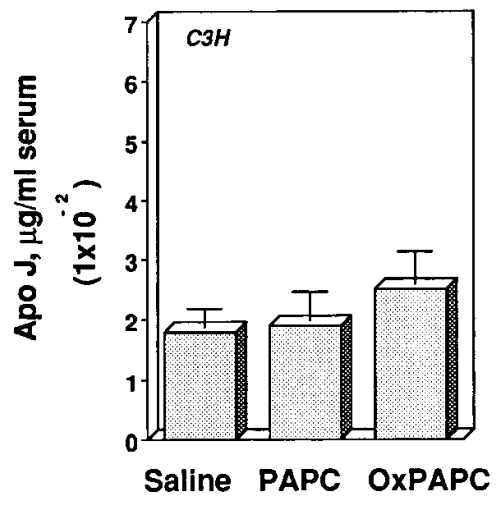

E

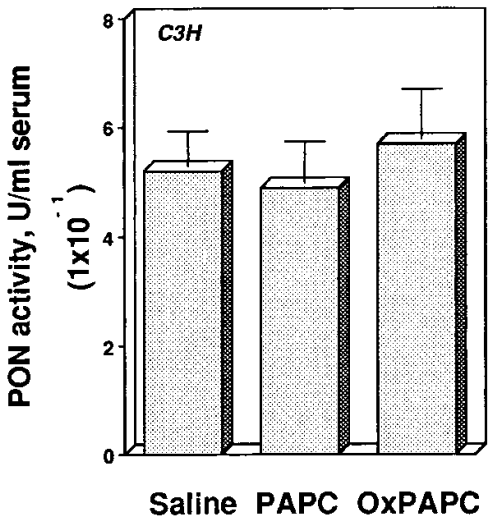

$\boldsymbol{F}$

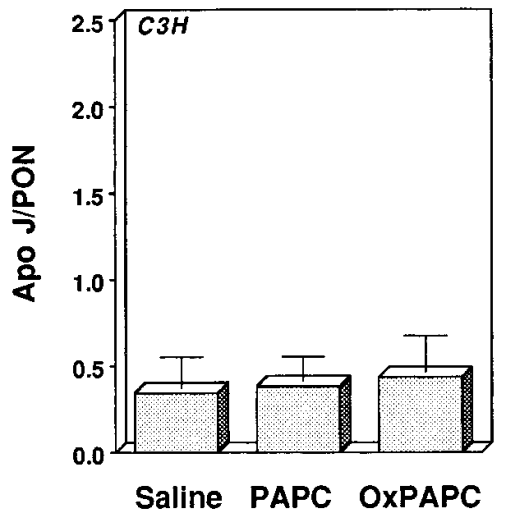

Figure 9. Effect of Ox-PAPC on serum PON and apoJ. Three groups of five BL/6 mice $(A-C)$ and three groups of five $\mathrm{C} 3 \mathrm{H}$ mice $(D-F)$ each maintained on the chow diet were injected with saline, $100 \mu \mathrm{g}$ authentic PAPC, or with $100 \mu \mathrm{g}$ PAPC that had been mildly oxidized at room temperature for $48 \mathrm{~h}$ (Ox-PAPC) as described in Methods. Blood samples were collected from retroorbital sinus, and apoJ levels $(A$ and $D)$ and PON activity $(B$ and $E$ ) were determined. $C$ and $F$ compare the apoJ/ $\mathrm{PON}$ ratios for the $\mathrm{BL} / 6$ and $\mathrm{C} 3 \mathrm{H}$ mice, respectively. The values represent mean $\pm \mathrm{SD}$ of measurements on triplicate plasma samples. $* P<0.02$. during the acute phase response (2.7-fold increase) or following the feeding of an atherogenic diet (2.8-fold increase). Shown in $B$ are the results from Western blot analyses, demonstrating a 2.1-fold increase in plasma apoJ protein during the acute phase response. A 2.4-fold increase was observed in plasma apoJ protein when the animals were fed the atherogenic diet. Hepatic PON mRNA showed a 2.7-fold reduction following feeding with the atherogenic $\operatorname{diet}(C)$.

\section{Studies in HepG2 cells}

Incubation of LDL that had previously been mildly oxidized by co-cultures of artery wall cells (CM-LDL) with HepG2 cells induced apoJ mRNA in the liver cells by a significant 2.1-fold (Fig. $11 A$ ). Native LDL did not increase the level of apoJ message. The effect of CM-LDL on liver cell PON mRNA was the opposite of that for apoJ. Incubation with CM-LDL reduced the liver cell PON message in culture by a significant 3.1-fold (Fig. $11 \mathrm{~B}$ ).

\section{Human studies}

Table I shows the plasma parameters for a subgroup of patients with angiographically documented coronary atherosclerosis who had normal plasma lipid levels, were not diabetic, and were not on lipid-lowering medications. There were no significant differences between the values for the patients compared to those for their age- and sex-matched controls, except for plasma apoJ levels which were on the average 3.3-fold higher among patients (Table I). This resulted in an apoJ/PON ratio of $3.0 \pm 0.4$ for the patients, as opposed to $0.72 \pm 0.2$ for the controls (4.2-fold higher in patients as compared to controls; $P<0.02)$. There was a trend for a reduction in the mean PON activity for patient plasma samples, but the difference did not 


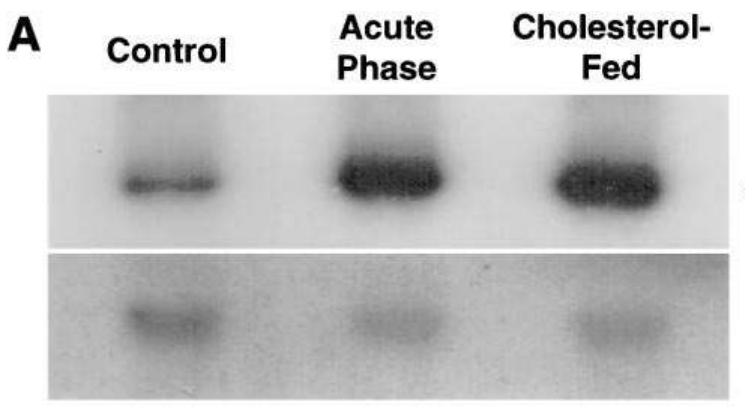

apo $J$

$18 s$

B

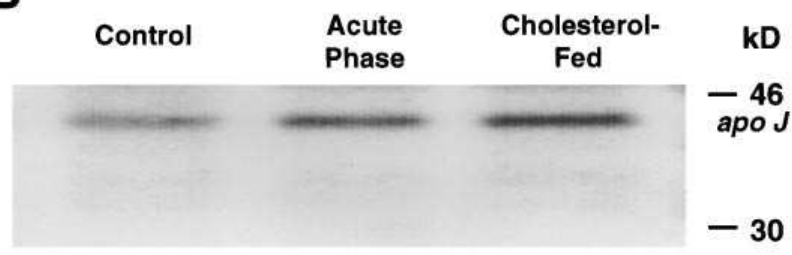

C Control CholesterolFed

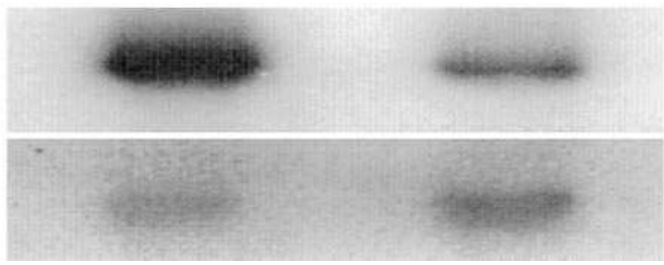

PON

$18 s$

Figure 10. (A) Hepatic expression of apoJ mRNA in normal, acute phase, and cholesterol-fed rabbits. Livers were removed from normal chow-fed or cholesterol-fed New Zealand white male rabbits, or chow-fed rabbits $72 \mathrm{~h}$ after injection with croton oil to induce an acute phase. Total RNA was isolated, and Northern blot analysis was carried out as described in Methods. Levels of mRNA for 18S ribosomal RNA are shown for normalization of the amount of RNA loaded into gel lanes. $(B)$ Plasma concentrations of apoJ. Blood was drawn from normal chow-fed or cholesterol-fed New Zealand white male rabbits or chow-fed rabbits $72 \mathrm{~h}$ after injection with croton oil, and Western blot analysis was carried out as described in Methods. Molecular weight markers are shown on the right. (C) Hepatic PON mRNA levels for rabbits. Livers were removed from normal chowfed or cholesterol-fed New Zealand white male rabbits. Total RNA was isolated, and Northern blot analysis for PON was carried out as described in Methods.

reach a significant level (Table I). There were no significant differences in the levels of serum amyloid A (SAA) and ceruloplasmin between the patients and controls (data not shown), indicating that the increase in apoJ levels in the patients undergoing coronary angiography was not because of an acute phase response resulting from the procedure. Indeed, in subjects undergoing angiography who did not demonstrate the presence of atherosclerosis $(n=9)$, the mean apoJ levels $(106 \pm 35 \mu \mathrm{g} /$ $\mathrm{ml}$ ) were not significantly different than the apoJ levels in controls $(74 \pm 29 \mu \mathrm{g} / \mathrm{ml})$. As shown in Fig. 12, $A$ and $B$, in a subset of the patients with coronary atherosclerosis $(n=5)$ the PON activity was low $(48 \pm 6.6 \mathrm{U} / \mathrm{ml})$ as compared to $98 \pm 17 \mathrm{U} / \mathrm{ml}$ for controls $(P<0.01)$ despite equal plasma concentrations of HDL ( $50 \pm 6.1$ vs $48.3 \pm 5.3 \mathrm{mg} / \mathrm{dl}$ for patients and controls, respectively) and despite similar total cholesterol/HDL choles-
A

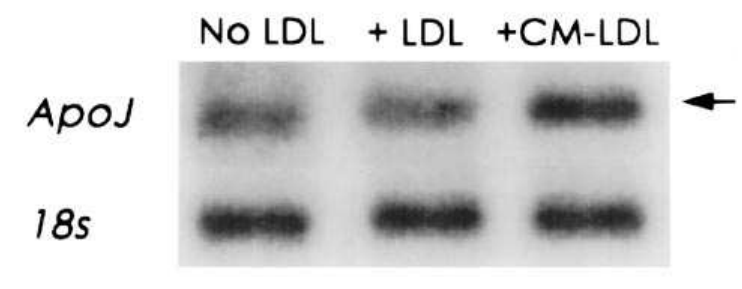

B

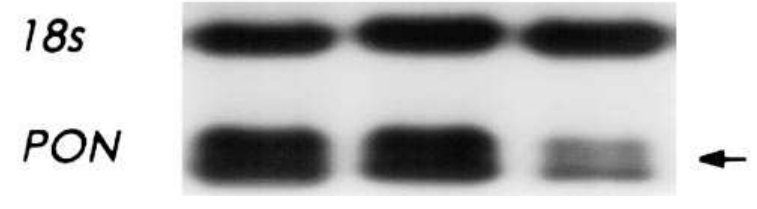

Figure 11. (A) Stimulation of HepG2 mRNA for apoJ by CM-LDL. HepG2 cells were cultured as described in Methods, and were incubated for $16 \mathrm{~h}$ in the absence of additional LDL, or in the presence of $350 \mu \mathrm{g} / \mathrm{ml}$ native LDL or co-culture modified LDL designated as CM-LDL. Total RNA was then isolated, and Northern blot analysis was carried out as described in Methods. Levels of mRNA for $18 \mathrm{~S}$ ribosomal RNA are shown for normalization of the amount of RNA loaded into gel lanes. $(B)$ Inhibition of HepG2 mRNA for PON by CM-LDL. HepG2 cells were cultured as described in Methods, and were incubated for $16 \mathrm{~h}$ in the absence of additional LDL, or in the presence of $350 \mu \mathrm{g} / \mathrm{ml}$ native LDL or CM-LDL. Total RNA was then isolated, and Northern blot analysis was carried out as described in Methods. Levels of mRNA for $18 \mathrm{~S}$ ribosomal RNA are shown for normalization of the amount of RNA loaded into gel lanes.

terol ratios ( $3.38 \pm 0.4$ vs $3.86 \pm 0.5$ for patients and controls, respectively). Fig. 12, $A$ and $B$ shows the mean and standard deviation for clinical parameters for four of the control subjects with normal PON $(A)$, and five patients with low HDL PON activity $(B)$, and demonstrate that they were significantly different in their apoJ and PON values. Results presented in Fig. 12, $C$ and $D$ demonstrate that the HDL from these pa-

Table I. Clinical Parameters for Patient and Control Subjects

\begin{tabular}{lcc}
\hline & Controls & Patients \\
\hline & $n=19$ & $n=14$ \\
Age (yr) & $53 \pm 6.9$ & $63 \pm 7.6$ \\
Plasma parameters: & & \\
Total cholesterol (mg/dl) & $178.1 \pm 21$ & $182.2 \pm 30$ \\
Triglycerides (mg/dl) & $78.3 \pm 30.2$ & $82.3 \pm 41.4$ \\
LDL cholesterol (mg/dl) & $94.5 \pm 31.1$ & $89.2 \pm 33.2$ \\
HDL cholesterol (mg/dl) & $62.3 \pm 14.5$ & $58.7 \pm 12.7$ \\
PON (U/ml) & $102.4 \pm 41.1$ & $80.8 \pm 28.2$ \\
Apo J $(\mu \mathrm{g} / \mathrm{ml})$ & $73.7 \pm 29.1$ & $246.1 \pm 79.4^{*}$ \\
Cholesterol/HDL & $2.86 \pm 0.61$ & $3.10 \pm 0.94$ \\
ApoJ/PON & $0.72 \pm 0.2$ & $3.04 \pm 0.4^{*}$ \\
& & \\
\hline
\end{tabular}

Plasma samples from patients and controls were subjected to analyses as described in Methods. The data were analyzed by ANOVA 1, and a paired Student's $t$ test was used to determine the level of significance. $* P<0.02$. 
$\boldsymbol{A}$

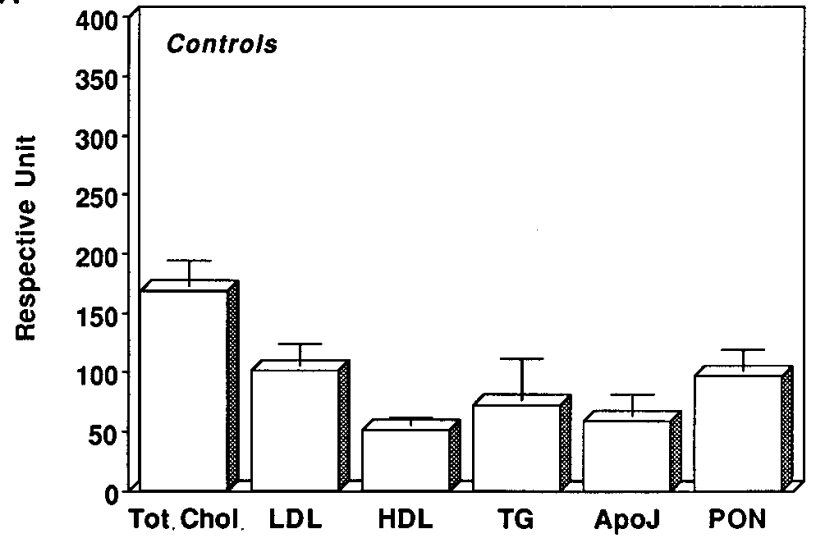

C

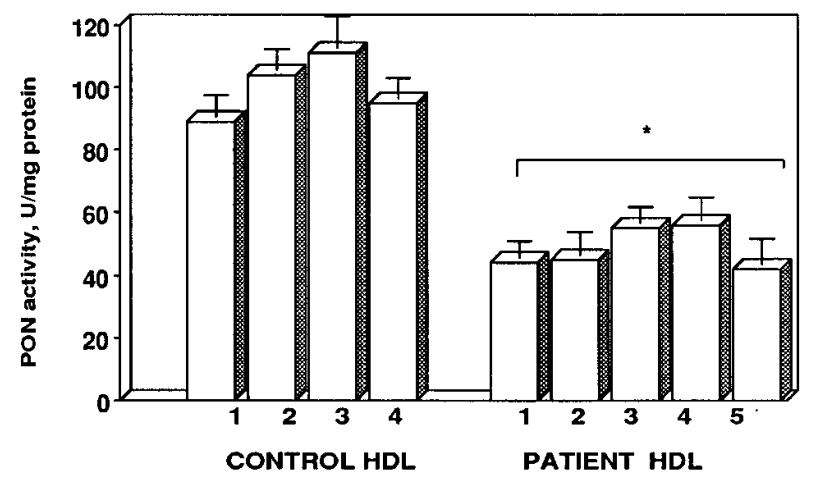

$\boldsymbol{B}$

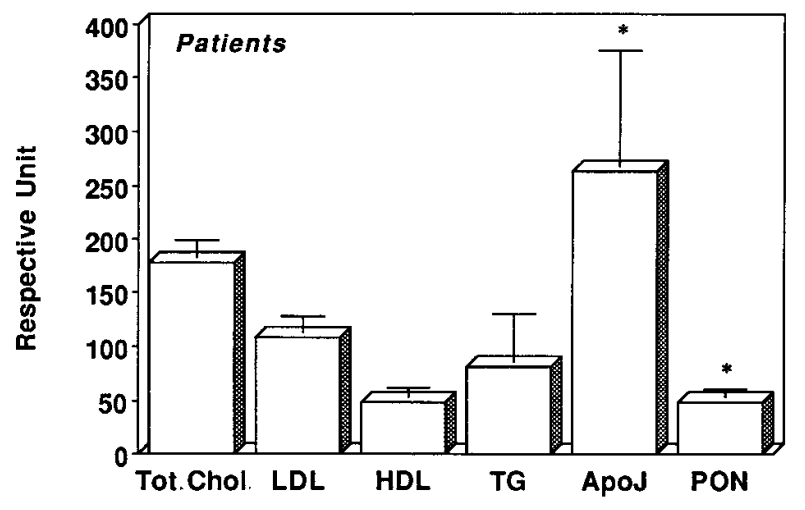

$\boldsymbol{D}$

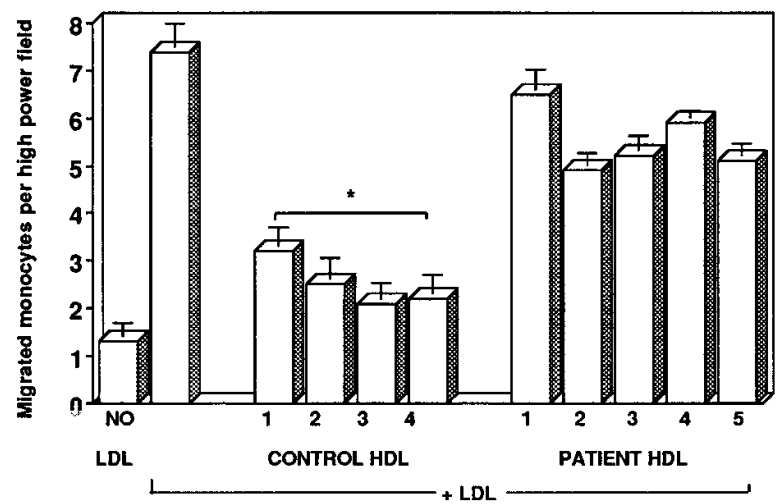

Figure 12. Lack of protection by HDL with low PON activity. Plasma lipids (in $\mathrm{mg} / \mathrm{dl}$ ), apoJ (in $\mu \mathrm{g} / \mathrm{ml}$ ) and PON activity (in U/ml) were measured for controls $(n=4, A)$ and for patients $(n=5, B)$ as described in Methods. $* P<0.01$. (C) HDL PON activity. Plasma HDL samples from four control subjects and from five patients with HDL cholesterol levels similar to those of the control HDL samples were analyzed for PON activity as described in Methods. The values represent mean \pm SD of triplicate determinations. Asterisk indicates a significant difference at $P<$ 0.01. (D) Protection against LDL-induced monocyte migration. HDL samples from the control subjects and from the patients were examined for protection against LDL-induced monocyte transmigration as described in Fig. 1. The values are mean \pm SD of the number of migrated monocytes in quadruple cocultures. $* P<0.03$.

tients with low PON activity failed to protect against LDLinduced monocyte migration in co-cultures of human artery wall cells, while the HDL from control subjects with normal PON activity was efficient in preventing LDL-induced monocyte migration (Fig. $12 \mathrm{D}$ ).

\section{Effect of paraoxonase isoforms on oxidized PAPC}

To compare the hydrolytic activity of different isoforms of purified PON, Ox-PAPC was incubated with PON Q or PON R initially in a test tube followed by examination in the co-culture system. As shown in Fig. 13, whereas isoform $\mathrm{R}$ was as expected, $(\sim 7.5$-fold more active in hydrolyzing paraoxon $)(A)$, there was no significant difference between the two isoforms in the ability to reduce the bioactivity of Ox-PAPC $(B)$.

\section{Discussion}

In population studies, the risk for an atherosclerotic event is strongly and inversely related to HDL levels (23). Currently, among the risk factors, the total cholesterol/HDL cholesterol ratio is considered to be the most predictive for atherosclerosis. The greater the ratio, the greater the risk for a clinical event. Individual patients, however, often deviate from the prediction, and a small but significant percentage of clinical events occur in patients with normal total cholesterol/HDL cholesterol ratios (24). The role of HDL in preventing atherosclerosis has long been thought to be because of its function in reverse cholesterol transport. Recent evidence from Rothblat's laboratory is consistent with this hypothesis when the results from a whole population are considered (24). Over the range of nearly a fourfold difference in HDL levels, however, there was only about a $50 \%$ difference in cholesterol efflux, and there were substantial individual variations in the HDL level and the degree of efflux induced by a particular subject's HDL (24). Thus, there remains the possibility that properties of HDL other than its ability to promote cholesterol efflux may play a role in its protective effect.

A role for oxidation of LDL lipids in the development of 

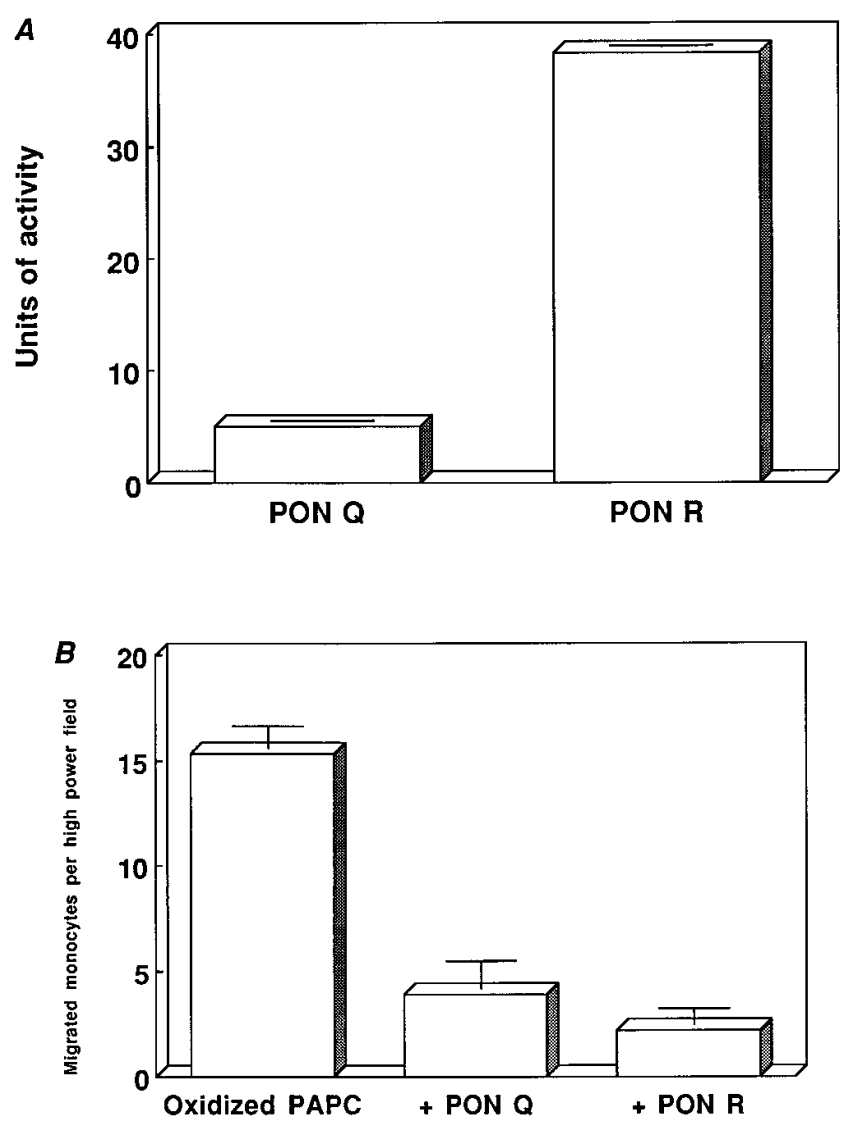

Figure 13. The activity of PON isoforms. (A) Purified human PON Q or PON R at $2 \mu \mathrm{g} / \mathrm{ml}$ were incubated with paraoxon and assayed for paraoxonase activity as described in the Methods. The data demonstrates the mean \pm SD of triplicate determinations. $(B)$ Oxidized PAPC at $50 \mu \mathrm{g} / \mathrm{ml}$ was incubated with buffer (designated as Oxidized PAPC), or Ox-PAPC plus PON Q (designated as +PON Q) or plus PON R (designated as +PON R) at $2 \mu \mathrm{g} / \mathrm{ml}$ in a test tube for $1 \mathrm{~h}$ at $37^{\circ} \mathrm{C}$ with gentle mixing. Samples were subsequently filtered through a 10,000 Mwt cutoff membrane to separate the paraoxonase $(43 \mathrm{kD})$ from Ox-PAPC. The sham-treated Ox-PAPC and PON-treated Ox-PAPC samples were then incubated with the co-cultures, and the resulting monocyte transmigration was subsequently determined as described for Fig. 1. The values are mean \pm SD of triplicate determinations.

atherosclerotic lesions has been firmly established over the past decade and a half (25-28), and a role for lipid oxidation in the causation of plaque rupture and thrombosis has recently been suggested (29-32). HDL has been found to protect against the oxidation of LDL by metal ions in vitro $(33,34)$, and was found to prevent the production of mildly oxidized LDL by artery wall cells in co-culture (1-5). HDL obtained either from patients undergoing surgery or after myocardial infarction in which apolipoprotein AI was displaced from the HDL by the acute phase reactant SAA, however, not only did not protect against LDL modification, but actually enhanced LDL modification by the co-cultures (3). Recent work from a number of laboratories has suggested that the protective effect of HDL may relate, in part, to enzymes associated with HDL $(35,36,1-4)$. The two-enzyme systems associated with normal HDL, platelet-activating factor acetylhydrolase, and PON are effective in preventing metal ion-dependent oxidation of LDL, and both of these enzymes have been shown to protect against LDL oxidation in the co-culture system $(1,2)$. These enzymes, which are associated with only 1 in 10 to 1 in 100 of the particles in the total plasma HDL, are capable of destroying the biologically active lipids that are generated in LDL when LDL becomes trapped in the artery wall cell co-culture system (1, 2 ), and possibly in the vessel wall in vivo. We previously demonstrated that PON is capable of abolishing the bioactivity of mildly oxidized LDL, and also that of Ox-PAPC. This was evident by the loss of the induction of monocyte adhesion and transmigration by mildly oxidized LDL or Ox-PAPC. This effect correlated with a marked reduction by PON of the 270 nm-absorbing material (carbonyl groups and conjugated trienes) in the phospholipids extracted from LDL that was mildly oxidized by co-cultures of artery wall cells (2).

The loss of the protective capacity of HDL from the fatty streak susceptible mice strain BL/6 on the atherogenic diet, against LDL-induced monocyte transmigration correlated with the low level of PON in this HDL (4). We have shown here that a similar defect exist in apoE knockout mice (Figs. 5 and 6), and in a subgroup of patients with low PON activity (Fig. 12). An increased apoJ/PON ratio was seen in the BL/6 mice on the atherogenic diet (Fig. $3 C$ ), in the apoE knockout mice (Fig. $5 E$ ), and in the LDL receptor knockout mice on an atherogenic diet (Fig. $7 \mathrm{E}$ ) as well as following injection into the BL/6 mice of CM-LDL (Fig. $8 \mathrm{C}$ ), or following injection of Ox-PAPC into BL/6 mice (Fig. $9 C$ ). Moreover, in the rabbit models of both the acute phase response and of hypercholesterolemia (Fig. 10), and following incubation of HepG2 cells with CM-LDL (Fig. 11), there was an increased apoJ/PON ratio. There was a marked increase in plasma apoJ levels in the patient population (Fig. $12 \mathrm{~B}$ ), and a tendency for reduced PON activity that resulted in an elevated apoJ/PON ratio (Table I).

Alterations in serum PON activity have been reported in several pathological conditions (for review see reference 37 ). Abbott and colleagues (38) and Mackness and Durrington (39) have reported low PON activity in diabetes, which was shown to be because of decreased specific activity. These observations were subsequently confirmed and extended (40). Mackness and colleagues then went on to demonstrate that the effect of HDL in decreasing LDL lipid peroxidation could only be fully explained if an enzymatic mechanism was involved (41). In earlier studies by these investigators, low serum PON activity was associated with increased susceptibility to atherosclerosis (42), and their recent results suggest an association of low serum PON with peripheral neuropathy, which could be because of reduced capacity to detoxify lipid peroxides in diabetes. Studies in 793 individuals of Hutterite Brethren, a genetic isolate characterized by high indices of relatedness and a communal agrarian lifestyle, suggest that PON is a significant genetic determinant of plasma levels of total cholesterol, HDL cholesterol, LDL cholesterol, and triglycerides (43). Additionally, a variant of human PON/arylesterase (HUMPONA) gene was shown to be a risk factor for coronary artery disease in a study involving 223 individuals with angiographically documented coronary atherosclerosis (44). Human serum PON is a polymorphic protein that occurs as two forms, different by one amino acid at position 192; glutamine in type Q (formerly type A), and arginine in type R (type B) (45). About $30 \%$ of Caucasians are homozygous for the R allozyme, 
and $40 \%$ are QR heterozygotes with the remainder classified as $\mathrm{Q}$ homozygotes. As previously established, and also observed with purified preparations in the present study, the PON R isozyme has nearly 8-fold greater activity against paraoxon than the $\mathrm{Q}$ allozyme. The two forms are, however, similar in their capacity to hydrolyze phenyl acetate, a reference aromatic ester (45). Most organophosphate and aromatic acid ester substrates examined so far follow a pattern similar to that for the hydrolysis of phenyl acetate (37). Fig. 13 demonstrates that the ability of the two isoforms of human serum PON for hydrolysis of ox-PAPC was also similar.

We have recently reported that HDL levels and PON levels were highly correlated in recombinant inbred strains of mice (4). It is therefore not surprising that most patients with normal HDL levels have normal PON activity. The finding, however, that 5 out of 14 patients with normal HDL levels had low PON activity was unexpected. The vast majority of the more than 250 patients that were screened to find the 14 with documented coronary atherosclerosis (which were normolipidemic, nondiabetic, and not on lipid lowering agents) revealed, as expected, that most atherosclerotic patients have low levels of HDL, and their PON activities were also low (data not shown). These patients also had increased apoJ levels (data not shown).

ApoJ, also known as clusterin, is a glycoprotein that is present in a subpopulation of HDL together with PON and apolipoprotein AI $(10,46)$, and has been reported to have diverse functions, including roles in complement regulation and prevention of cytolysis (47), lipid transport (48), apoptosis (49, $50)$, and membrane protection at fluid-tissue interfaces where it is expressed (51). These properties have led to the suggestion that apoJ may protect vascular endothelium against attack by factors such as those in the terminal complement cascade. ApoJ has been classified as a positive acute phase protein (52). Administration of endotoxin, tumor necrosis factor, or interleukin-1 increased hepatic mRNA and serum protein levels of apoJ in Syrian hamsters (51). Moreover, apoJ was found to be increased in tissues undergoing wound repair, and in atherosclerotic lesions $(53,54)$. ApoJ was reported to circulate in plasma as an HDL complex, which may serve not only as an inhibitor of the lytic terminal complement cascade, but also as a regulator of lipid transport and local lipid redistribution (55).

In the present study, preincubation of LDL or artery wall cells in co-culture with purified apoJ revealed a dose-dependent inhibition of LDL-induced lipid hydroperoxide formation, MCP-1 production, and monocyte transmigration (data not shown). These observations suggest that apoJ is capable of reducing the oxidative potential of LDL and of the artery wall cells (Fig. 1). The mechanism likely involves the removal by apoJ of lipid oxidation products that have been proposed to be generated by the cells, or are associated with LDL (19-21). In ongoing studies, we have observed (by electrospray ionizationmass spectrometry) the presence of several compounds in lipid extracts from apoJ after incubation with LDL or with cells (data not shown). The regions of the apoJ molecule containing antiparallel ladder-like structures between the two chains have been suggested to be capable of binding lipids, and the presence of alpha-helical regions could be related to the lipid binding functions of apoJ (56). That apoJ is secreted from HepG2 cells as a lipoprotein indicates its ability to be associated with lipids (57). It is possible that the marked increase in plasma apoJ levels during inflammatory conditions, including in athero- genesis, allows it to serve a protective role through its diverse biological interactions.

In the present study, induction of hepatic apoJ following an acute phase response or upon feeding a high-cholesterol diet in rabbits confirms our observations in mice. The sixfold increase in the ratio of messages for apoJ to PON in HepG2 cells after incubation with mildly oxidized LDL indicates that the effect of the biologically active CM-LDL is likely exerted at the level of the liver cell. ApoJ levels were on average 3.3-fold higher among patients with documented coronary artery disease who had normal lipid profiles, were free of diabetes, and were not on medications affecting their lipid levels. Reduced PON activity and increased apoJ levels resulted in a 4.2-fold increase in the apoJ/PON ratio for the patients compared to controls. The presence of similar levels of SAA and ceruloplasmin between the patients and controls (data not shown) excludes the possibility of an acute phase response by the angiography procedure.

In contrast to the differences in the apoJ/PON ratio, there were no significant differences between the values for plasma platelet-activating factor acetylhydrolase activity in the patients and the controls $(6.5 \pm 0.71$ vs. $7.2 \pm 0.84 \mathrm{U} / \mathrm{ml}$ for patients and controls, respectively, data not shown). Moreover, HDL from the patients and controls induced similar cholesterolefflux from cholesterol-loaded human monocyte-macrophages ( $43 \pm 12 \%$ vs. $51 \pm 14 \%$ of the cellular cholesterol removed by the patient, and control HDL respectively, data not shown).

In the patients with coronary atherosclerosis with normal HDL levels, but with low PON activity, their HDL failed to protect against LDL-induced monocyte migration in the cocultures while the HDL from control subjects with normal PON activity was efficient in preventing LDL-induced monocyte migration $(1-5,58)$. Thus, the inverse relationship between the risk for atherosclerotic events and HDL levels may be because of enzymes associated with HDL that protect against LDL oxidation as well as the putative role of HDL in reverse cholesterol transport and in lipid redistribution. Moreover, since these enzymes are associated with only a small fraction of HDL particles, this may explain in part why some patients with low levels of total HDL cholesterol may not have clinically significant atherosclerosis, and others with relatively normal levels of HDL cholesterol may have premature atherosclerosis. Kelso and colleagues (10) reporting on their biochemical studies on the physical association of plasma apoJ and PON suggested that the link of apoJ with PON might be implicated as a predictor of vascular damage. The data generated in the present study demonstrating that normolipidemic patients with normal total cholesterol/HDL cholesterol ratios had an increased apoJ/PON ratio renders the latter an attractive candidate for predicting the presence of atherosclerosis.

The evidence presented here both in vitro and in vivo in multiple species suggests that prospective investigations including larger studies of the role of apoJ and PON in predicting atherosclerosis are warranted.

\section{Acknowledgments}

We thank Dr. M.D. Griswold and his colleagues for the generous gifts of pure murine apoJ and antibody to apoJ; Dr. Lawrence A. Yeatman and the members of the cath lab team at the UCLA CHS for careful collection of patient blood samples; Cynthia Harper and Alan Wagner for recruiting and phlebotomy of the control subjects and 
providing the core support; Bobby Harris, Rachel Mottahedeh, Jerika Lam, Sam Koutal, Angela Achevery, and Diane Lee for expert technical assistance, and Trung and Thao Nguyen for their excellent data analyses. We are thankful to members of the heart transplant team for providing the donor aortic specimens for isolation of the artery wall cells.

This work was supported in part by the U.S. Public Health Services grants HL 30568 and RR-865, by the Laubisch and M.K. Grey Funds, and by the Cigarette and Tobacco Surtax Fund of the State of California through the Tobacco-Related Disease Research Program at the University of California.

\section{References}

1. Watson, A.D., M. Navab, S.Y. Hama, A. Sevanian, S.M. Prescott, D.M. Stafforini, T.M. McIntyre, B.N. La Du, A.M. Fogelman, and J.A. Berliner. 1995. Effect of platelet activating factor-acetylhydrolase on the formation and action of minimally oxidized low density lipoprotein. J. Clin. Invest. 95:774-782.

2. Watson, A.D., J.A. Berliner, S.Y. Hama, B.N. La Du, K.F. Faull, A.M. Fogelman, and M. Navab. 1995. Protective effect of high-density lipoprotein associated PON. Inhibition of the biological activity of minimally oxidized low density lipoprotein. J. Clin. Invest. 96:2882-2891.

3. Van Lenten B.J., S.Y. Hama, F.C. deBeer, D.M. Stafforini, T.M. McIntyre, S.M. Prescott, B.N. La Du, A.M. Fogelman, and M. Navab. 1995. Antiinflammatory HDL becomes pro-inflammatory during the acute phase response. Loss of protective effect of HDL against LDL oxidation in aortic wall cell cocultures. J. Clin. Invest. 96:2758-2767.

4. Shih, D.M., L. Gu, S. Hama, Y. Xia, M. Navab, A.M. Fogelman, and A.J. Lusis. 1996. Genetic-dietary regulation of serum paraoxonase expression and its role in atherogenesis in a mouse model. J. Clin. Invest. 97:1630-1639.

5. Navab, M., S.S. Imes, S.Y. Hama, G.P. Hough, L.A. Ross, R.W. Bork, A.J. Valente, J.A. Berliner, D.C. Drinkwater, H. Laks, and A.M. Fogelman. 1991. Monocyte transmigration induced by modification of low-density lipoprotein in co-cultures of human aortic wall cells is due to induction of monocyte chemotactic protein 1 synthesis, and is abolished by high density lipoprotein. $J$. Clin. Invest. 88:2039-2046.

6. Havel, R.J., H.A. Eder, and J.H. Bragdon. 1955. The distribution and chemical composition of ultracentrifugally separated lipoproteins of human serum. J. Clin. Invest. 43:1345-1353.

7. Warden, C.H., J.H. Qiao, L.W. Castellani, and A.J. Lusis. 1993. Atherosclerosis in transgenic mice overexpressing apolipoprotein A-II. Science (Wash. DC). 261:469-472.

8. Auerbach, B.J., J.S. Kiely, and J.A. Cornicelli. 1992. A spectrophotometric microtiter-based assay for the detection of hydroperoxy derivatives of linoleic acid. Anal. Biochem. 201(2):375-380.

9. Fogelman, A.M., K. Sykes, B.J. Van Lenten, M.C. Territo, and J.A. Berliner. 1988. Modification of the Recalde method for the isolation of human monocytes. J. Lipid Res. 29:1243-1247.

10. Kelso, G.J., W.D. Stuart, R.J. Richter, C.E. Furlong, T.C. JordanStarck, and J.A. Harmony. 1994. Apolipoprotein J is associated with paraoxonase in human plasma. Biochemistry. 33:832-839.

11. Griswold, M.D., K. Roberts, and P. Bishop. 1986. Purification and characterization of a sulfated glycoprotein secreted by Sertoli cells. Biochemistry. 25:7265-7270.

12. Gan, K.N., A. Smolen, H.W. Eckerson, and B.N. La Du. 1991. Purification of human serum paraoxonase/arylesterase. Evidence for one esterase catalyzing both activities. Drug Metab. Dispos. 19:100-106.

13. Cabana, V.G., J.N. Siegel, and S.M. Sabesin. 1989. Effects of the acute phase response on the concentration and density distribution of plasma lipids and apolipoproteins. J. Lipid Res. 30:39-49.

14. Laemmli, U.K. 1970. Cleavage of structural proteins during the assembly of the head of bacteriophage. Nature (Lond.). 227:680-685.

15. Chomczynski, P., and N. Sacchi. 1987. Single step method of RNA isolation by acid guanidinium thiocyanate-phenol-chloroform extraction. Anal. Biochem. 162:156-159.

16. Doolittle, M.H., R.C. LeBoeuf, C.H. Warden, L.M. Bee, and A.J. Lusis. 1990. A polymorphism affecting apolipoprotein A-II translational efficiency determines high density lipoprotein size and composition. J. Biol. Chem. 265: $16380-16388$.

17. Lorenzen, A., and S.W. Kennedy. 1993. A fluorescence based protein assay for use with a microplate reader. Anal. Biochem. 214:346-348.

18. Lowry, O.H., M.J. Rosebrough, A.L. Farr, and R.J. Randall. 1951. Protein measurement with the Folin phenol reagent. J. Biol. Chem. 193:265-275.

19. Steinberg, D., S. Parthasarathy, T.E. Carew, J.C. Khoo, and J.L. Witztum. 1989. Beyond cholesterol-Modifications of low density lipoprotein that increase its atherogenicity. N. Engl. J. Med. 320:915-924.

20. Witztum, J.L., and D. Steinberg. 1991. Role of oxidized low density lipoprotein in atherogenesis. J. Clin. Invest. 88:1785-1792.
21. Parthasarathy, S. 1994. Modified Lipoproteins in the Pathogenesis of Atherosclerosis. R. G. Landes Co., Austin, TX. 91-119.

22. Lusis, A.J., and M. Navab. 1993. Lipoprotein oxidation and gene expression in the artery wall: New opportunities for pharmacologic intervention in atherosclerosis. Biochem. Pharmacol. 46:2119-2126.

23. Gordon, D.J., J.L. Probstfield, R.N. Garrison, J.D. Neaton, W.P. Castelli, J.D. Jacobs Jr., S. Bangdiwala, and H.A. Tyroler. 1989. High density lipoprotein cholesterol and cardiovascular disease. Circulation. 79:8-15.

24. de la Llera Moya, M., V. Atger, J.L. Paul, N. Fournier, N. Moatti, P. Giral, E.K. Friday, and G. Rothblat. 1994. A cell culture system for screening human serum for ability to promote cellular cholesterol efflux. Relations between serum components and efflux, esterification, and transfer. Arterioscler. Thromb. 14:1056-1065.

25. Hessler, J.R., A.L. Robertson, Jr., and G.M. Chisolm. 1979. LDL-induced cytotoxicity and endothelial cells in culture. Arteriosclerosis. 32:213-229.

26. Parthasarathy, S. 1994. Mechanism(s) of cell-mediated oxidation of low density lipoprotein. Free Radicals in the Environment, Medicine, and Toxicology. H. Nohl, H. Esterbauer, and C. Rice Evans, editors. Richelieu Press, London. 163-179.

27. Witztum, J.L. 1994. The oxidation hypothesis of atherosclerosis. Lancet. 344:793-795.

28. Chisolm, G.M. 1991. Antioxidants and atherosclerosis: a current assessment. Clin. Cardiol. 14:125-130.

29. Fuster, V., L. Badimon, J.J. Badimon, and J.H. Chesebro. 1992. The pathogenesis of coronary artery disease and the acute coronary syndromes. $N$. Engl. J. Med. 326:242-250, 310-318.

30. Buja, L.M., and J.T. Willerson. 1994. Role of inflammation in coronary plaque disruption. Circulation. 89:503-505.

31. van der Wal, A.C., A.E. Becker, C.M. van der Loos, and P. Das. Site of intimal rupture or erosion of coronary atherosclerotic plaques is characterized by an inflammatory process irrespective of the dominant plaque morphology. Circulation. 89:36-44.

32. Galis, Z.S., G.K. Sukhova, M.W. Lark, and P. Libby. 1994. Increased expression of matrix metalloproteinases and matrix degrading activity in vulnerable regions of human atherosclerotic plaques. J. Clin. Invest. 94:2493-2503.

33. Parthasarathy, S., J. Barnett, and L.G. Fong. 1990. High-density lipoprotein inhibits the oxidative modification of low-density lipoprotein. Biochim. Biophys. Acta. 1044:275-283.

34. Ohta, T., K. Takata, S. Horiuchi, Y. Morino, and I. Matsuda. 1989. Protective effect of lipoproteins containing apoprotein A-I on $\mathrm{Cu} 2^{+}$-catalyzed oxidation of human low density lipoprotein. FEBS (Fed. Eur. Biochem. Soc.) Lett. 257:435-438.

35. Mackness, M.I., S. Arrol, and P.N. Durrington. 1991. Paraoxonase prevents accumulation of lipoperoxides in low-density lipoprotein. FEBS (Fed. Eur. Biochem. Soc.) Lett. 286:152-154.

36. Stafforini, D.M., G.A. Zimmerman, T.M. McIntyre, and S.M. Prescott. 1993. The platelet activating factor acetylhydrolase from human plasma prevents oxidative modification of low density lipoprotein. Trans. Assoc. Am. Phys. 105:44-63.

37. La Du, B.N. 1992. Human serum paraoxonase/arylesterase, in Pharmacogenetics of Drug Metabolism. W. Kalow, editor. Pergamon Press, Inc., Tarrytown, NY. 51-91.

38. Abbott, C.A., M.I. Mackness, S. Kumar, A.J. Boulton, and P.N. Durrington. 1995. Serum paraoxonase activity, concentration, and phenotype distribution in diabetes mellitus and its relationship to serum lipids and lipoproteins. Arterioscler. Thromb. Vasc. Biol. 11:1812-1818.

39. Mackness, M.I., and P.N. Durrington. 1995. Paraoxonase: another factor in NIDDM cardiovascular disease. Lancet. 346:856. Letter.

40. Mackness, M.I., S. Arrol, C.A. Abbott, and P.A. Durington. 1993. Protection of low density lipoprotein against oxidative modification by high density lipoprotein paraoxonase. Atherosclerosis. 104:129-135.

41. Mackness, M.I., C.A. Abbott, S. Arrol, and P.A. Durington. 1993. The role of high-density lipoprotein and lipid soluble antioxidant vitamins in inhibiting low density lipoprotein oxidation. Biochem. J. 294:829-834.

42. McElveen, J., M.I. Mackness, C.M. Colley, T. Peard, S. Warner, and C.H. Walker. 1986. Distribution of paraoxon hydrolytic activity in the serum of patients after myocardial infarction. Clin. Chem. 32:671-673.

43. Hegele, R.A., J.H. Brunt, and P.W. Connelly. 1995. A polymorphism of the paraoxonase gene associated with variation in plasma lipoproteins in a genetic isolate. Arterioscler. Thromb. Vasc. Biol. 15:89-95.

44. Serrato, M., and A.J. Marian. 1995. A variant of human paraoxonase/ arylesterase (HUMPONA) gene is a risk factor for coronary artery disease. $J$. Clin. Invest. 96:3005-3008.

45. La Du, B.N. 1996. Structural and functional diversity of paraoxonases. Nat. Med. 2:1186-1187.

46. Blatter, M.-C., R.W. James, S. Messmer, F. Barja, and D. Pometta. 1993. Identification of a distinct human high-density lipoprotein subspecies defined by a lipoprotein-associated protein, K-45, Identity of K-45 with paraoxonase. Eur. J. Biochem. 211:871-879.

47. Tschopp, J., and L.E. French. 1994. Clusterin: modulation of complement function. Clin. Exp. Immunol. 97 (Suppl. 2):11-14.

48. Rosenberg, M.E., and J. Silkensen. 1995. Clusterin: physiologic and 
pathophysiologic considerations. Int. J. Biochem. Cell Biol. 27:633-645.

49. Wong, P., J. Pineault, J. Lakins, D. Taillefer, J. Leger, C. Wang, and M. Tenniswood. 1993. Genomic organization and expression of the rat TRPM-2 (clusterin) gene, a gene implicated in apoptosis. J. Biol. Chem. 268:5021-5031.

50. French, L.E., A. Wohlwend, A.P. Sappino, J. Tschopp and A. Schifferli. 1994. Human clusterin gene expression is confined to surviving cells during in vitro programmed cell death. J. Clin. Invest. 93:877-884.

51. Aronow, B.J., S.D. Lund, T.L. Brown, J.A. Harmony, and D.P. Witte. 1993. Apolipoprotein $\mathbf{J}$ expression at fluid-tissue interfaces: potential role in barrier cytoprotection. Proc. Natl. Acad. Sci. USA. 90:725-729.

52. Hardardottir, I., S.T. Kunitake, A.H. Moser, W.T. Doerrler, J.H. Rapp, C. Grunfeld, and K.R. Feingold. 1994. Endotoxin and cytokines increase hepatic messenger RNA levels and serum concentrations of apolipoprotein J (clusterin) in Syrian hamsters. J. Clin. Invest. 94:1304-1309.

53. Witte, D.P., B.J. Aronow, M.L. Stauderman, W.D. Stuart, M.A. Clay, R.A. Gruppo, S.H. Jenkins, and J.A. Harmony. 1993. Platelet activation releases megakaryocyte-synthesized apolipoprotein $\mathrm{J}$, a highly abundant protein in atheromatous lesions. Am. J. Pathol. 143:763-773.
54. Jordan-Starck, T.C., S.D. Lund, D.P. Witte, B.J. Aronow, C.A. Ley, W.D. Stuart, D.K. Swertfeger, L.R. Clayton, S.F. Sells, B. Paigen et al. 1994. Mouse apolipoprotein J: characterization of a gene implicated in atherosclerosis. J. Lipid Res. 35:194-210.

55. Jenne, D.E., B. Lowin, M.C. Peitsch, A. Bottcher, G. Schmitz, and J. Tschopp. 1991. Clusterin (complement lysis inhibitor) forms a high density lipoprotein complex with apolipoprotein A-I in human plasma. J. Biol. Chem. 266: 11030-11036.

56. Choi-Miura, N.H., Y. Takahashi, Y. Nakano, T. Tobe, and M. Tomita. 1992. Identification of the disulfide bonds in human plasma protein SP-40,40 (apolipoprotein-J). J. Biochem. (Tokyo). 112:557-561.

57. Burkey, B.F., W.D. Stuart, and J.A. Harmony. 1992. Hepatic apolipoprotein $\mathrm{J}$ is secreted as a lipoprotein. J. Lipid Res. 33:1517-1526.

58. Navab, M., J.A. Berliner, A.D. Watson, S.Y. Hama, M.C. Territo, A.J. Lusis, D.M. Shih, B.J. Van Lenten, J.S. Frank, L.L. Demer, P.A. Edwards, and A.M. Fogelman. 1996. The Yin and Yang of oxidation in the development of the fatty streak. A review based on the 1994 George Lyman Duff memorial lecture. Arterioscler. Thromb. Vasc. Biol. 16:831-842. 